\title{
An MRI-compatible varus-valgus loading device for whole-knee joint functionality assessment based on compartmental compression: a proof-of-concept study
}

\author{
Oliver Said ${ }^{1}$ Justus Schock ${ }^{2,3}$. Nils Krämer ${ }^{1}$. Johannes Thüring ${ }^{1}$ - Lea Hitpass ${ }^{1}$. Philipp Schad ${ }^{1}$. Christiane Kuhl ${ }^{1}$. \\ Daniel Abrar ${ }^{2} \cdot$ Daniel Truhn $^{1,3}$. Sven Nebelung ${ }^{2}$
}

Received: 29 January 2020 / Revised: 27 March 2020 / Accepted: 6 April 2020 / Published online: 20 April 2020

(c) The Author(s) 2020, corrected publication 2021

\begin{abstract}
Objective Beyond static assessment, functional techniques are increasingly applied in magnetic resonance imaging (MRI) studies. Stress MRI techniques bring together MRI and mechanical loading to study knee joint and tissue functionality, yet prototypical axial compressive loading devices are bulky and complex to operate. This study aimed to design and validate an MRI-compatible pressure-controlled varus-valgus loading device that applies loading along the joint line.

Methods Following the device's thorough validation, we demonstrated proof of concept by subjecting a structurally intact human cadaveric knee joint to serial imaging in unloaded and loaded configurations, i.e. to varus and valgus loading at $7.5 \mathrm{kPa}(=73.5 \mathrm{~N}), 15 \mathrm{kPa}(=147.1 \mathrm{~N})$, and $22.5 \mathrm{kPa}(=220.6 \mathrm{~N})$. Following clinical standard (PDw fs) and high-resolution 3D water-selective cartilage (WATSc) sequences, we performed manual segmentations and computations of morphometric cartilage measures. We used CT and radiography (to quantify joint space widths) and histology and biomechanics (to assess tissue quality) as references.

Results We found (sub)regional decreases in cartilage volume, thickness, and mean joint space widths reflective of areal pressurization of the medial and lateral femorotibial compartments.

Discussion Once substantiated by larger sample sizes, varus-valgus loading may provide a powerful alternative stress MRI technique.
\end{abstract}

Keywords Loading $\cdot$ Stress MRI $\cdot$ Knee joint $\cdot$ Cartilage $\cdot$ Varus

\section{Introduction}

Electronic supplementary material The online version of this article (https://doi.org/10.1007/s10334-020-00844-6) contains supplementary material, which is available to authorized users.

Sven Nebelung

sven.nebelung@med.uni-duesseldorf.de

1 Department of Diagnostic and Interventional Radiology, Aachen University Hospital, Aachen, Germany

2 Department of Diagnostic and Interventional Radiology, Medical Faculty, University Hospital Düsseldorf, University Dusseldorf, Moorenstraße 5, 40225 Düsseldorf, Germany

3 Institute of Computer Vision and Imaging, RWTH University Aachen, Aachen, Germany
Magnetic resonance imaging (MRI) is clearly the most powerful and versatile technique for musculoskeletal imaging. Providing the reference standard imaging modality for the non-invasive assessment of intra- and periarticular structures of the human knee joint, current clinical-standard morphological MRI studies are usually performed with the patient in a supine position and their joints in an unloaded and, consequently, unphysiological configuration.

In the past, numerous scanner setups and work-around devices implementing in situ loading have been devised for the sake of more physiological examination conditions. By design, open MRI scanners can examine the patient in a standing or seated position, thereby enabling imaging of the lower extremity under weight-bearing [1,2]. The undisputed diagnostic benefits of joint imaging in a loaded configuration, however, are realized at the expense of reduced image 
quality secondary to significantly lower field strengths (i.e. $B_{0} \leq 0.5 \mathrm{~T}$ ), signal-to-noise ratios, and image resolutions [3]. This in turn challenges the reliable detection of slight changes in the intraarticular soft tissues' morphological appearance [4].

For example, when loaded with half the patient's body weight, decreases in articular cartilage thickness amount to $3-8 \%$ of the initial thickness, equalling absolute deformations of 0.06-0.08 $\mathrm{mm}$ [5]. More specifically, the medial femoral condyle undergoes significant relative changes in cartilage thickness of $-3.3 \pm 7.1 \%$ (normal knees) and -7.9 $\pm 11.0 \%$ (OA knees) $(p=0.097)$. Relative changes in the medial tibia $[-6.9 \pm 14.1 \%$ (normal); $-6.2 \pm 10.5 \%(\mathrm{OA})$; $p=0.443]$ and the lateral tibia $[-4.4 \pm 10.3 \%$ (normal); $-5.0 \pm 8.5 \%(\mathrm{OA}) ; p=0.452]$ are less related to degeneration, while changes in the lateral femoral condyle $[-1.0 \pm$ 9.7\% (normal); $1.9 \pm 8.3 \%$ (OA); $p=0.243$ ] are considerably less related to loading [5]. Hence, in such functional joint studies, it is pivotal to realize optimized image resolutions and signal-to-noise ratios while maintaining clinically acceptable examination times. As higher field strength may be invested in faster image acquisition, this aspect requires the use of high-field MRI scanners. For these, various prototypical MRI-compatible loading devices for stress MRI in vivo, i.e. for loading a patient's knee joint(s), have been developed to date [6]. Positioned inside the scanner's closed horizontal bore along with the patient, these devices provide an alternative way of loading while preserving high imaging standards at feasible examination times. Even though the exact mechanism of loading is different, all these devices apply axial loading along the joint axis, either by suspending weights via dedicated pulley systems $[5,7-10]$ or by direct compressive loading in a displacement-controlled [11] or pressure-controlled manner $[12,13]$. Also, all these devices require mechanical fixation of the patient which renders them bulky, complex, and inconvenient to operate and use. Load application along the leg axis inevitably induces knee flexion (and tibial rotation) [14], which may be partially reduced by immobilization, yet challenges standardization and intra- and inter-patient reproducibility [5, 12]. Despite promising results that indicated the potential of these functional imaging techniques in several experimental and clinical contexts [15], their clinical use is still limited to date.

Against the background of increasing interest in the association of joint mechanics and joint imaging with a traditional focus on cartilage, an alternative approach may be loading of the knee joint along the joint line, i.e. in a varus or valgus configuration, to induce compartmental pressurization of the medial or lateral femorotibial joint compartment. On similar grounds, varus-valgus stress radiography has been applied over the past decades to assess compartmental degeneration in osteoarthritis (OA) in more functional contexts [16-18]. Thereby, quantification of cartilage thickness and tissue laxity was improved as compared to alternative radiographic techniques [17-19], yet clinical adoption was limited due to radiation exposure, impossible direct soft tissue evaluation, and the acquisition of projection radiographs only. Consequently, the fine graduation of early-to-moderate degenerative and non-degenerative cartilage changes by stress radiography remains elusive $[17,20]$.

Therefore, the present study aimed to bring together varus-valgus loading (VVL) and MRI to improve functional cartilage and joint assessment. This study's objectives were (1) to design, construct, and validate an MRI-compatible pressure-controlled VVL device for standardized compartmental loading of human knee joints; (2) to demonstrate proof of concept by subjecting a human cadaveric knee joint to a range of VVL intensities and determining MR imaging, computed tomography (CT), and radiographic measures; and (3) to reference these measures to histological and conventional biomechanical measures of sampled joint regions. Consequently, we hypothesized that (1) by means of the VVL device, the medial and lateral femorotibial compartments may be loaded in a standardized, consistent, and reproducible manner and (2) loading-induced adaptive processes within the joint may be reliably detected based on high-resolution morphological MRI techniques, correlated with CT and radiographic measures, and associated with the joint position and loading configuration.

\section{Materials and methods}

\section{Study design}

This study was divided into two parts: (1) the development, construction, and validation of an MRI-compatible pressurecontrolled VVL device; and (2) its proof-of-concept application in studying changes within a human cadaveric knee joint based on MR imaging, CT and radiography and as a function of gradually increased VVL intensities.

\section{Varus-valgus loading (VVL) device}

\section{System design}

The MRI-compatible pressure-controlled VVL device was laid out as a leverage mechanism, i.e. a central pressure applicator and two opposed counter-bearings as fixed points. Principally, the device consists of a loading and a separate control unit (Fig. 1).

The loading unit is made of synthetic MRI-compatible materials such as poly(ether-ether-ketone) (PEEK), polymethyl-methacrylate (PMMA), and polyvinyl-chloride (PVC). The solid base plate (PVC, height $5 \mathrm{~cm}$, width 48 $\mathrm{cm}$, length $51 \mathrm{~cm}$ ) contains full-thickness openings (for 

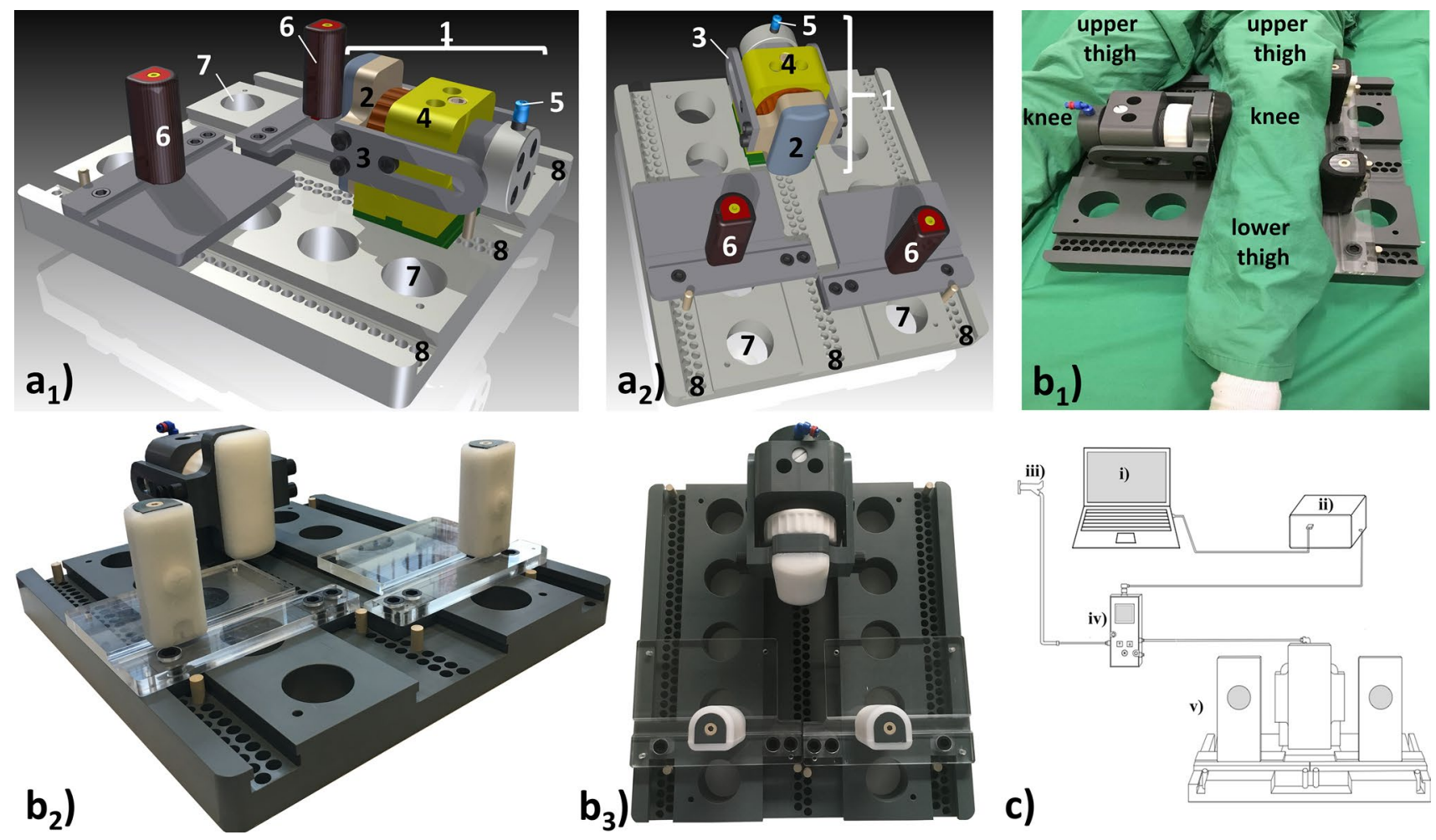

Fig. 1 MRI-compatible pressure-controlled varus-valgus loading device [CAD schemes (a) and photographs (b)] and schematic overview of loading and control unit (c). a Principally, the pneumatic mechanism (1) consists of the padded pressure applicator (2), safety rails (3) on both sides of the encasement (4) and the loading piston (not shown). The pneumatics are fed remotely via pressure tubes that are connected via pressure port (5). On the opposite side, equally padded counter-bearings (6) to be repositioned in the $X$ and $Y$ planes ensure reproducible loading of the knee joint with the lower extremity in an anatomical and physiological configuration. The entire setup is mounted on a stable base plate containing openings (7, for weight reduction) and grooves ( 8 , for flexible and symmetrical positioning of the components). b Device loaded with a left lower extremity $\left(\mathbf{b}_{\mathbf{1}}\right)$ and unloaded viewed from the side $\left(\mathbf{b}_{\mathbf{2}}\right)$ and from the top $\left(\mathbf{b}_{3}\right)$. In this setup, the pneumatic mechanism is located at the medial side of the left knee, i.e. in varus loading. c Via laptop (i) and conversion device (ii), the pressure level as provided by the hospital's in-house pressure outlets (iii) is regulated by the pressure control valve (iv) and forwarded to the device (v)

both sides of the encasement mechanically prevent excessive (and potentially injurious) thrusting of the pressure applicator against the knee joint. On the opposite side of the pneumatic mechanism, counter-bearings ensure reproducible force application by preventing horizontal displacement of both upper and lower thigh. The counter-bearings are semicircular (PVC, length: $12 \mathrm{~cm}$, width: $3.5 \mathrm{~cm}$, depth: $3.5 \mathrm{~cm}$ ) and circumferentially surrounded by silicone rubber of 1.0 cm thickness (Dragon Skin ${ }^{\circledR}$ FX-Pro). To account for any interindividual differences in patient anatomy, the counterbearings are mounted on transparent plates (PMMA, width: $18 \mathrm{~cm}$, length: $24 \mathrm{~cm}$ ) and may be repositioned in the $X$ plane. Correspondingly, the pneumatic mechanism and the two counter-bearings may also be set in various positions along the longitudinal grooves and in the $Y$ plane. Fixation of the individual components is realized by locking pins (PEEK) that prevent lateral displacement. The setup may be mirrored for variable VVL configurations of both knee joints. 

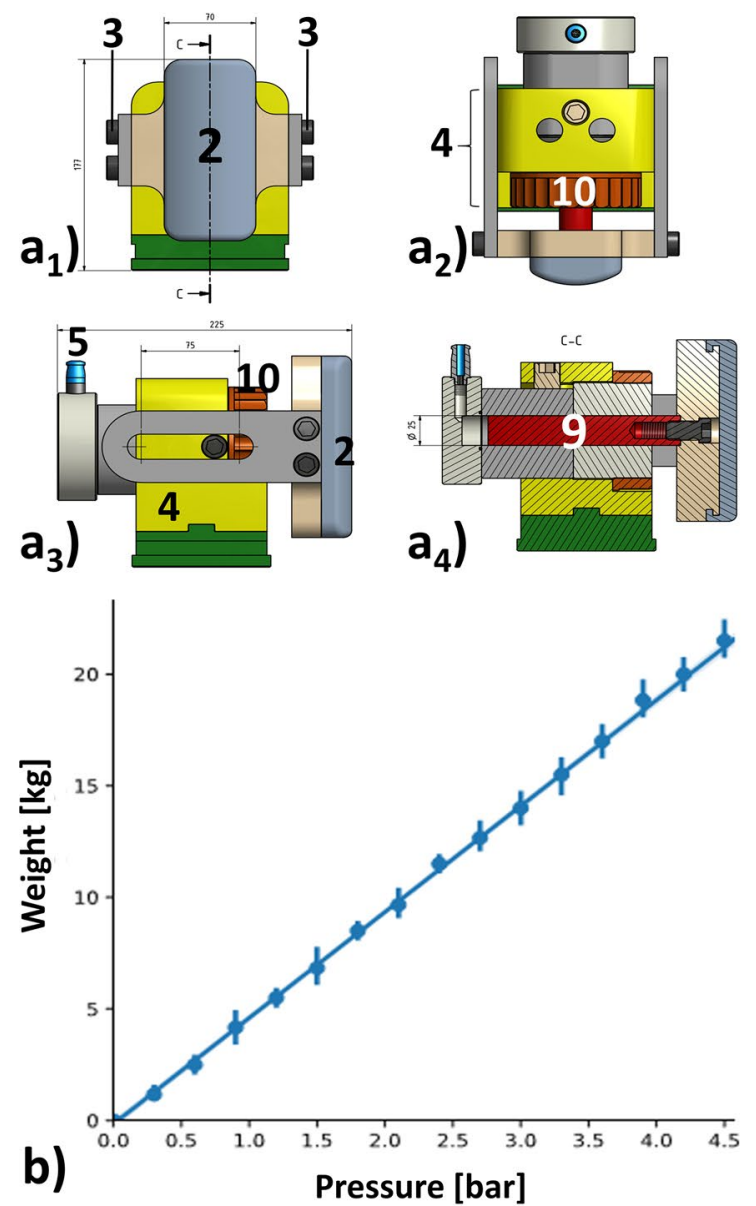

Fig. 2 CAD schemes of the pneumatics (a), pressure vs. weight calibration curve (b), and operation of the MRI-compatible varus-valgus loading device in a 3.0-T MRI scanner (Achieva, Philips) (c). a Front view $\left(\mathbf{a}_{1}\right)$, top view $\left(\mathbf{a}_{2}\right)$, side view $\left(\mathbf{a}_{3}\right)$, and central cross-section $\left(\mathbf{a}_{\mathbf{4}}\right)$ of the pneumatics. The loading piston (9) has a diameter of $25 \mathrm{~mm}$ $(=2.5 \mathrm{~cm})$ and may be adjusted in its horizontal position by means of a coarse set screw (10). Otherwise, component numbering and color coding as in Fig. 1. Units of dimensions are (mm). b Theoretical (solid line) and measured (data points) associations between set

\section{Control unit}

The associated control unit is located outside of the MRI scanner room and consists of a digital-to-analogue converter (Multifunction I/O USB-6001, National Instruments, Austin, US) and an electronically actuated pressure valve (VPPM6L-L-1-G18-0L6H-V1P-S1C1, Festo). Via standard pressure lines these components connect the loading device with the in-hospital pressure outlets that provide pressure levels of up to 4.69 bar. The digital-to-analogue converter is controlled by customized software routines (LabVIEW, National Instruments) and, in turn, controls the pressure valve to any target pressure level from 0 to 4.69 bar. Of note, any compatible air compressor device may be used as alternative pressure source.
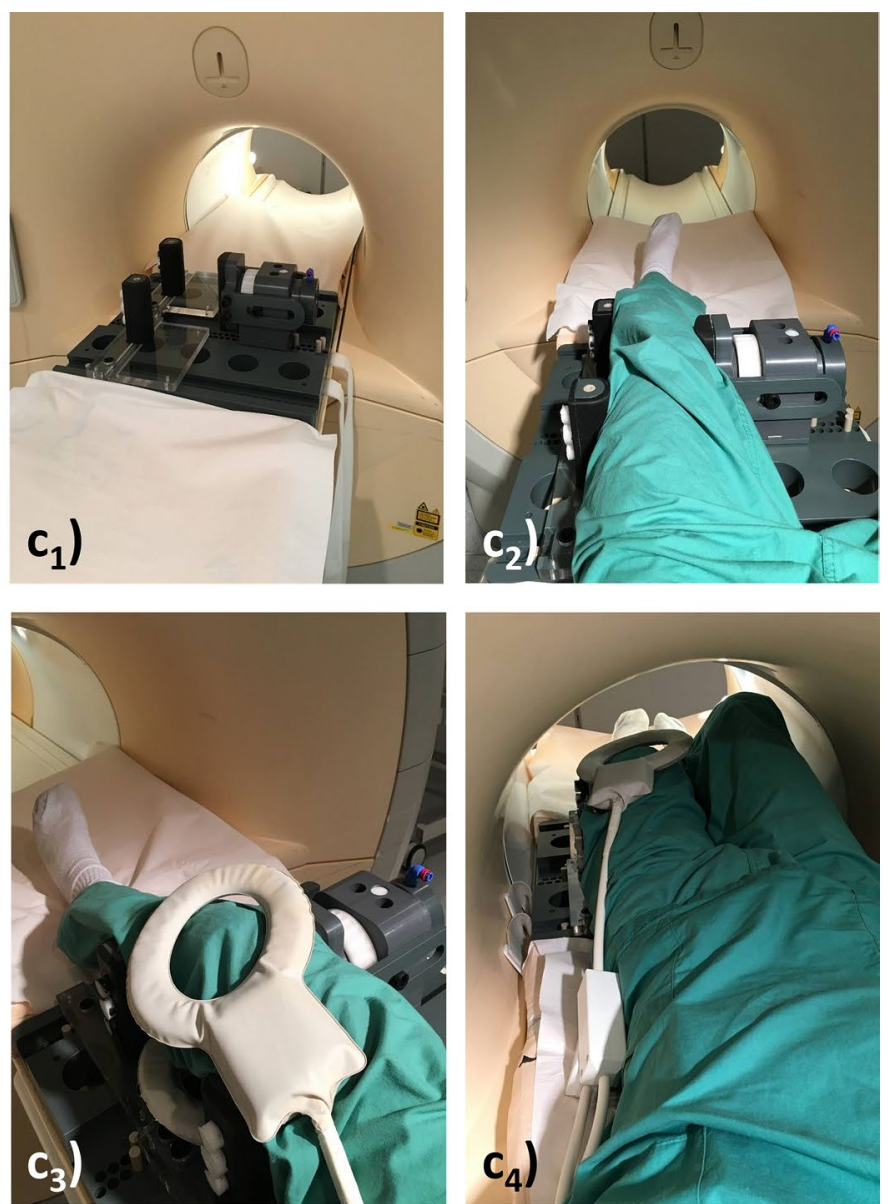

pressure levels ( $x$-axis) and resultant weights or forces ( $y$-axis) are plotted. Points give means, while bars give standard deviations (of three measurements). c Stepwise loading for eventual MR imaging, i.e. device in the unloaded configuration positioned on the patient bed $\left(\mathbf{c}_{1}\right)$ and loaded with the senior author's left lower extremity for varus loading $\left(\mathbf{c}_{2}\right)$. Multi-purpose measurement coils were used for MR imaging and positioned above and below the knee joint $\left(\mathbf{c}_{\mathbf{3}}\right)$. Final measurement position in the scanner with the contralateral lower extremity placed on the pneumatics $\left(\mathbf{c}_{\mathbf{4}}\right)$

Set pressure levels act on a cylindrical pneumatic piston within the device. At the maximum set pressure of 4.69 bar, the piston therefore generates theoretical forces of $230.2 \mathrm{~N}$ (pneumatic piston: diameter $25 \mathrm{~mm}$; cross-sectional area: $490.9 \mathrm{~mm}^{2}$ ). As pressure is freely adjustable in the range of 0-4.69 bar, the resultant calculated forces on the pneumatic piston range between 0 and $230.2 \mathrm{~N}$. Force is rigidly transferred to the pressure applicator which is consecutively displaced towards the joint. This force range is reflective of commonly applied force levels for conventional stress radiography of the human knee joint [21]. 


\section{Pressure-force calibration}

Mechanical validation of the VVL device and its pneumatic control was performed using a digital hydraulic force gauge [\#HKMD29D, Induk, Wuppertal, Germany, specifications: pressure range $0-2.5 \mathrm{kN}$; accuracy $\pm 1.0 \%$ (of full scale)]. In practical terms, we positioned the load cell between the pressure applicator (without padding) and both counter-bearings that were clamped by a rigid PVC plate. We then determined resultant forces transmitted to the load cell through the pressure applicator for increasing pressure levels set at intervals of 0.3 bar. We repeated these measurements three times and calculated mean forces as a function of set pressure levels. For data analysis, we determined Pearson's correlation coefficient $r$ using the library SciPy in Python (Python Software Foundation, Version 3.6.5) [22] (Fig. 2b). Moreover, we also assessed force levels in a longitudinal manner, i.e. as a function of time. To this end, mean force levels at a constant pressure level of 3 bar were measured every minute over a period of $30 \mathrm{~min}$.

\section{Human cadaveric knee joint}

One fresh and structurally intact left human cadaveric knee joint from a male body donor, who had deceased due to unrelated medical conditions at the age of 78 years, was obtained from the Department of Anatomy (RWTH Aachen University, Germany). Of note, local Institutional Review Board approval (Ethical Committee, RWTH Aachen University, AZ-EK180/16) and written informed consent by the body donor were available at study initiation.

In preparation of the MRI measurements, the human cadaveric knee joint was positioned in slight flexion of approximately $20^{\circ}$ by placing appropriate positioning aids underneath the joint. Additionally, we used mechanical positioners such as sandbags to reduce joint motion in response to loading. In varus or valgus loading, the medial or lateral joint line was brought in line with the centre of the padded pressure applicator. Both counter-bearings were adjusted to the anatomy of the knee joint at the greatest possible distance from each other. Attention was paid that the loading components were in loose contact with the knee joint, i.e. the counter-bearings with the lower and upper thirds of the femur and tibia and the pressure applicator with the medial or the lateral joint line.

\section{Imaging studies}

\section{MRI studies}

The VVL device was loaded with the human cadaveric knee joint and centrally positioned in the bore of a clinical 3.0-T scanner (Achieva, Philips, The Netherlands) (Fig. 2c).
Imaging was performed using a general-purpose dual-coil configuration (Sense-Flex L, Philips) with the coils being placed above and below the joint where they were attached with medical adhesive tape to prevent displacement during loading. The presence of the loading components made the use of a dedicated multi-channel knee coil impossible due to space constraints. In preparation of the actual MRI measurements, the presence of image artefacts was assessed using dedicated $B_{0}$ and $B_{1}$ mapping sequences (as provided by the manufacturer, Philips) acquired with a water phantom with and without the loading device in position. Moreover, we used a $\mathrm{T} 2 *$-weighted $2 \mathrm{D}$ gradient-echo sequence (time to repetition $=702.5 \mathrm{~ms}$, echo time $=16.1 \mathrm{~ms}$, flip angle $=$ $18^{\circ}, 22$ slices, slice thickness $=5 \mathrm{~mm}$, slice gap $=15.5$ $\mathrm{mm}$, field of view $=467 \mathrm{~mm} \times 467 \mathrm{~mm}$, acquisition matrix $=256 \times 205$, number of signal averages $=1$; Q-body coil; coronal orientation) to assess the presence of image artefacts because of the loading device. Once the connections and system operability were checked, we performed the MRI measurements in seven distinct configurations: (1) unloaded $\left(\delta_{0}\right)$, (2) valgus load of $7.5 \mathrm{kPa}\left(=73.5 \mathrm{~N}, \delta_{\mathrm{vlg} 1}\right)$, (3) valgus load of $15 \mathrm{kPa}\left(=147.1 \mathrm{~N}, \delta_{\mathrm{vlg} 2}\right)$, (4) valgus load of $22.5 \mathrm{kPa}\left(=220.6 \mathrm{~N}, \delta_{\mathrm{vlg} 3}\right),(5)$ varus load of $7.5 \mathrm{kPa}\left(\delta_{\mathrm{var} 1}\right)$, (6) varus load of $15 \mathrm{kPa}\left(\delta_{\mathrm{var} 2}\right)$, and (7) varus load of 22.5 $\mathrm{kPa}\left(\delta_{\mathrm{var} 3}\right)$. Of note, pressure levels were set by digital control. Throughout the study, equilibration periods of $5 \mathrm{~min}$ were observed after each change in pressure level. For each loading position, fat-saturated 2D proton density-weighted (PD-fs) sequences and 3D water-selective cartilage scans (WATSc) were acquired. Please see Table 1 for details of the chosen sequence parameters. The PD-fs sequences are frequently used for imaging of the knee joint and articular cartilage $[23,24]$ and were acquired in the sagittal, axial and coronal planes $\left(\delta_{0}\right)$ and the axial and coronal planes $\left(\delta_{\mathrm{vlg} 1}, \delta_{\mathrm{vlg} 2}, \delta_{\mathrm{vlg} 3}, \delta_{\mathrm{var} 1}, \delta_{\mathrm{var} 2}\right.$, and $\left.\delta_{\mathrm{var} 3}\right)$, respectively. The WATSc sequence was acquired in the coronal plane and used to perform cartilage segmentations and morphometric measurements [25]. Based on the scout views and the PD-fs sequences, we checked the appropriate joint position within the device and measurements were performed in the seven joint configurations in the order $1-7$ as detailed above. The measurements were performed at room temperature. Total magnet time was approximately $3.5 \mathrm{~h}$.

\section{CT studies}

Analogously, the human cadaveric knee joint was scanned sequentially in the craniocaudal direction using a multidetector-row clinical CT scanner (SOMATOM Force, Siemens, Erlangen, Germany) and the following scan parameters: tube voltage $120 \mathrm{kV}$, tube current $800 \mathrm{mAs}$, slice thickness $0.6 \mathrm{~mm}$, rotation time $1 \mathrm{sec}$, increment 3 $\mathrm{mm}$, pitch 0.8 . After adapting the field of view $(158 \mathrm{~mm}$ 
Table 1 Acquisition parameters of MR sequences

\begin{tabular}{|c|c|c|}
\hline & PDW fs & WATSc \\
\hline Orientation & cor, ax (sag) & Cor \\
\hline Type of fat saturation & SPAIR & $\begin{array}{l}\text { Water- } \\
\text { selective } \\
\text { excitation }^{\mathrm{a}}\end{array}$ \\
\hline Sequence type & Turbo spin echo & Gradient echo \\
\hline Repetition time (ms) & 4776 & 10 \\
\hline Echo time (ms) & 30 & 5 \\
\hline Turbo spin-echo factor & 13 & 1 \\
\hline Field of view (mm) & $180 \times 180$ & $180 \times 180$ \\
\hline Acquisition matrix & $368 \times 364$ & $368 \times 368$ \\
\hline Reconstruction matrix & $512 \times 512$ & $512 \times 512$ \\
\hline Scan percentage $(\%)$ & 100 & 78.5 \\
\hline Flip angle $\left(^{\circ}\right)$ & 90 & 17 \\
\hline Number of signal averages & 1 & 1 \\
\hline Slices & 33 & 266 \\
\hline Slice thickness/gap (mm) & $3.0 / 3.5$ & $1.5 / 0.0^{\mathrm{b}}$ \\
\hline Duration (min) & $5 \min 34 s-6 \min 39 s$ & $9 \min 30 \mathrm{~s}$ \\
\hline
\end{tabular}

Of note, the PDW-fs sequences were obtained in the cor, ax, and sag orientations in the unloaded reference configuration, while in all other configurations, they were only obtained in the cor and ax orientations $P D W$ proton density-weighted, WATSc water-selective cartilage scan, SPAIR spectral attenuated inversion recovery, $f s$ fat-saturated, $n / a$ not applicable, cor coronal, $a x$ axial, sag sagittal

${ }^{a}$ Because of its robustness towards $B_{0}$ magnetic field inhomogeneities, the binomial scheme 1331 was used for water-selective excitation

${ }^{\mathrm{b}} \mathrm{A}$ slice increment of $0.75 \mathrm{~mm}$ was present, i.e. the centres of two consecutive slices were $0.75 \mathrm{~mm}$ apart

$\times 158 \mathrm{~mm})$ to the joint outline, the chosen matrix $(512 \times$ 512 ) resulted in a pixel size of $0.31 \mathrm{~mm} \times 0.31 \mathrm{~mm}$. Scan duration was $5.28 \mathrm{~s}$ per joint configuration. For image reconstructions, the Siemens kernel Br64s was used and axial, coronal and sagittal reconstructions were obtained. As for MR imaging, the CT measurements were carried out in all joint configurations $\left(\delta_{0}, \delta_{\mathrm{vlg} 1}, \delta_{\mathrm{vlg} 2}, \delta_{\mathrm{vlg} 3}, \delta_{\mathrm{var} 1}\right.$, $\delta_{\text {var2 } 2}$, and $\delta_{\text {var3 }}$ ) using the pressure-controlled VVL device. An equilibration period of $5 \mathrm{~min}$ was observed after each change in pressure.

\section{Radiographic studies}

Stress radiography was performed using the commercially available Telos GA-III/E device (Telos $\mathrm{GmbH}$ ) at $20^{\circ}$ of knee flexion. Using standard settings for clinical radiography of the knee $(60 \mathrm{kV}, 4 \mathrm{mAs}$, variable focus-to-detector distance), anteroposterior projection radiographs of the knee were obtained in the following configurations: $\delta_{0}$, $\delta_{\mathrm{vlg} 1}, \delta_{\mathrm{vlg} 2}, \delta_{\mathrm{var} 1}$, and $\delta_{\mathrm{var} 2}$. Loading to $22.5 \mathrm{kPa}$ (i.e. $\delta_{\mathrm{vlg} 3}$, $\delta_{\text {var3 }}$ ) is not possible with this device.

\section{Post-processing and image analysis}

\section{MRI studies}

MR images of the human cadaveric knee joint were processed separately and in each configuration. Morphometric measurements of the medial and lateral femorotibial cartilage were based on manual segmentations and computations using Chondrometrics software (Chondrometrics $\mathrm{GmbH}$, Ainring, Germany) as published before, e.g. [26, 27]. On the basis of the 3D WATS-c sequences, the subchondral bone plates and cartilage surfaces of the medial and lateral femorotibial compartments were segmented manually in each image. Readers were blinded to the joint's configuration and reading quality was checked by an expert reader. Mean cartilage thickness over the subchondral bone was computed based on the segmented bone interface and cartilage surface by generation of 3D reconstructed cartilage surface areas. Subsequently, cartilage morphometric measures were quantified for each loading position. The mean cartilage thickness (ThC) was determined in the medial and lateral femorotibial compartments (MFTC, LFTC), the medial and lateral tibia (MT, LT), the medial and lateral central (i.e. weight-bearing) femur (cMF, cLF), five tibial subregions (central, external, internal, anterior, and posterior) of MT and LT, and three femoral subregions (central, external, and internal) of cMF and cLF. Moreover, cartilage volumes (VC) and cartilage surface areas (AC) were computed based on the manual segmentations and determined for the MT, LT, cMF, and cLF.

\section{$\mathrm{CT}$ and radiographic studies}

For CT analyses, sagittal and axial reconstructions were used to identify the coronal reference plane as the coronal imaging slice that centrally bisected the weight-bearing region of the MFTC and LFTC at the centre of the anteroposterior distance between the deepest point of the trochlear groove and the posterior condylar line. To this end, the joint space widths, i.e. the vertical distances between the subchondral bone contours of the tibial and femoral condyles, were measured at three locations per compartment, i.e. at the inner, central, and outer third. Similarly, joint space widths were measured at three locations on the projection radiographs. Mean joint space width was calculated for each loading position, compartment, and modality.

In addition, potential positional changes of the knee joint in response to loading were determined in terms of joint flexion and rotation. Flexion angle was determined between the femoral and tibial shafts on sagittal reconstructions. Rotation was measured as the angle between the device's horizontal base plate and a line that joined both corners of the patella on axial reconstructions. One reader (OS, 2 years of experience in MSK radiology) who was blinded to the 
joint configuration performed these measurements for each joint configuration using the inbuilt calliper tool of the clinical-routine picture archiving and communications system (PACS, iSite, Philips, The Netherlands). For visualization purposes, shaded CT volume renderings were generated using IntelliSpace Clinical Applications (Philips). Because of variable flexion and rotation at the different loading configurations, the knee joint (as the volume-of-interest) was defined and subsequently rolled and rotated to allow for unobstructed visualization of both joint spaces.

\section{Reference evaluation}

Immediately after completion of imaging studies, femorotibial pressure levels as a function of gradually increasing VVL were spatially mapped in the human cadaveric knee joint using digital electronic pressure-sensitive sensors (K-Scan 4000, 1.500 psi, Tekscan, Boston, MA, US). This system has been used widely in static and dynamic pressure mappings of the human knee joint [28, 29]. Its pressure-sensitive area measures $33 \mathrm{~mm} \times 27.9 \mathrm{~mm}$ (height $\times$ width) and contains 62 sensor elements $/ \mathrm{cm}^{2}$ to map maximum pressures of up to $103.42 \mathrm{bar}(=10342 \mathrm{kPa})$. Due to its flexible and thin configuration (thickness: $0.1 \mathrm{~mm}$ ), the area conforms to the individual knee joint anatomy. After accessing the joint via a medial parapatellar approach, the sensors were inserted into the medial and lateral compartments covering the femoral articular surfaces. Care was taken to avoid crinkling of the sensor areas and to cover the medial- and lateral-most portions of the compartments. However, due to limitations in sensor area, only the anterior two-thirds of the tibiofemoral articular surface were covered. To gain access to the joint, the collateral and cruciate ligament complex had to be partially cut. Prior to the measurements, sensors were preconditioned and calibrated in line with the manufacturer's instructions. Then, the knee joint was placed into the VVL device and loaded in six configurations, while equilibration periods of $5 \mathrm{~min}$ were observed after setting each loading position: $7.5 \mathrm{kPa}$ varus $\left(\delta_{1 \mathrm{var}}\right), 15 \mathrm{kPa}$ varus $\left(\delta_{2 \mathrm{var}}\right), 22.5 \mathrm{kPa}$ varus $\left(\delta_{3 \mathrm{var}}\right), 7.5 \mathrm{kPa}$ valgus $\left(\delta_{1 \mathrm{vlg}}\right), 15 \mathrm{kPa}$ valgus $\left(\delta_{2 \mathrm{vlg}}\right)$, and $22.5 \mathrm{kPa}$ valgus $\left(\delta_{3 \mathrm{vlg}}\right)$. Reasoning behind the choice of these loading intensities involves the most commonly used device for stress radiography, i.e. the Telos device (Telos $\mathrm{GmbH}$, current version GA-III/E, Wölfersheim-Berstadt, Germany), which uses $15 \mathrm{kPa}(=147.2 \mathrm{~N})$. The raw data obtained from these measurements were imported into Matlab (MatlabR2018b, Natick, USA) and analysed using customized analysis routines.

Next, the central weight-bearing femoral and tibial joint surfaces were identified and the peripheral femoral and tibial cartilage areas as well as the meniscus body regions were sampled to undergo histological and biomechanical reference assessment as published before [30-34] (see Supplementary File 1 for a detailed description).

\section{Results}

Validation of the pressure-force relationship revealed a close-to-perfectly linear association (Pearson's $r=0.999, p$ $<0.001$ ) between set pressure levels and resultant weights or forces (Fig. 2b). Consequently, set pressures of 1.62 bar, 3.23 bar, and 4.84 bar brought about weights (or forces) of $7.5 \mathrm{~kg}(=73.6 \mathrm{~N}), 15 \mathrm{~kg}(=147.2 \mathrm{~N})$ and $22.5 \mathrm{~kg}(225 \mathrm{~N})$, respectively. Longitudinal assessment of resultant forces at the set pressure level of 3 bar revealed constant measured forces of $130 \mathrm{~N}$ and, hence, no loss in force over $30 \mathrm{~min}$. Reference pressure mappings using pressure-sensitive sensors resulted in total forces over the entire loaded sensor area of $14.7 \mathrm{~N}\left(\delta_{\mathrm{vlg} 1}\right), 46.6 \mathrm{~N}\left(\delta_{\mathrm{vlg} 2}\right), 50.3 \mathrm{~N}\left(\delta_{\mathrm{vlg} 3}\right), 13.1 \mathrm{~N}\left(\delta_{\mathrm{var} 1}\right)$, $37.7 \mathrm{~N}\left(\delta_{\mathrm{var} 2}\right)$, and $38.6 \mathrm{~N}\left(\delta_{\mathrm{var} 3}\right)$.

No significant magnetic field inhomogeneity or image artefacts were associated with the presence of the loading device inside the scanner as indicated by $B_{0}$ or $B_{1}$ mapping and the T2*-weighted sequence, respectively. Overall, handling of the device, positioning of the human cadaveric knee joint and pressure-controlled application of force during MRI and CT studies was realized without difficulties. We did not encounter any adverse or unexpected events. Consequently, the knee joint underwent the MRI, CT and radiographic studies as planned in all configurations.

For MRI studies, qualitative evaluation revealed that the medial femorotibial articulation gradually narrowed in size with increasing varus loading intensity, while the lateral femorotibial articulation was gradually distended (Fig. 3a, b). Corresponding changes in both compartments were observed in response to increasing valgus loading intensity (Fig. 3a, c).

Quantitative evaluation of cartilage morphometric measures, i.e. $\mathrm{VC}$ and $\mathrm{ThC}$, were reflective of these changes throughout the various loading configurations (Table 2). In the MFTC, VC and ThC decreased in response to increasing varus loading, while these parameters remained largely unchanged (or increased slightly) in response to increasing valgus loading, e.g. mean ThC (cMF): $1.727 \mathrm{~mm}\left(\delta_{0}\right)$; $1.558 \mathrm{~mm}\left(\delta_{\mathrm{var} 3}\right) ; 1.724 \mathrm{~mm}\left(\delta_{\mathrm{vlg} 3}\right)$. Corresponding findings were made for the LFTC, where ThC of the lateral femur was slightly decreased in response to valgus loading and increased in response to varus loading, e.g. mean ThC (cLF): $1.637 \mathrm{~mm}\left(\delta_{0}\right) ; 1.735 \mathrm{~mm}\left(\delta_{\mathrm{var} 3}\right) ; 1.591 \mathrm{~mm}\left(\delta_{\mathrm{vlg} 2}\right) ; 1.622$ $\mathrm{mm}\left(\delta_{\mathrm{vlg} 3}\right)$. Generally, changes in VC and ThC of the LFTC in response to valgus loading were less clearly associated with loading intensity than the corresponding changes in the MFTC in response to varus loading. 

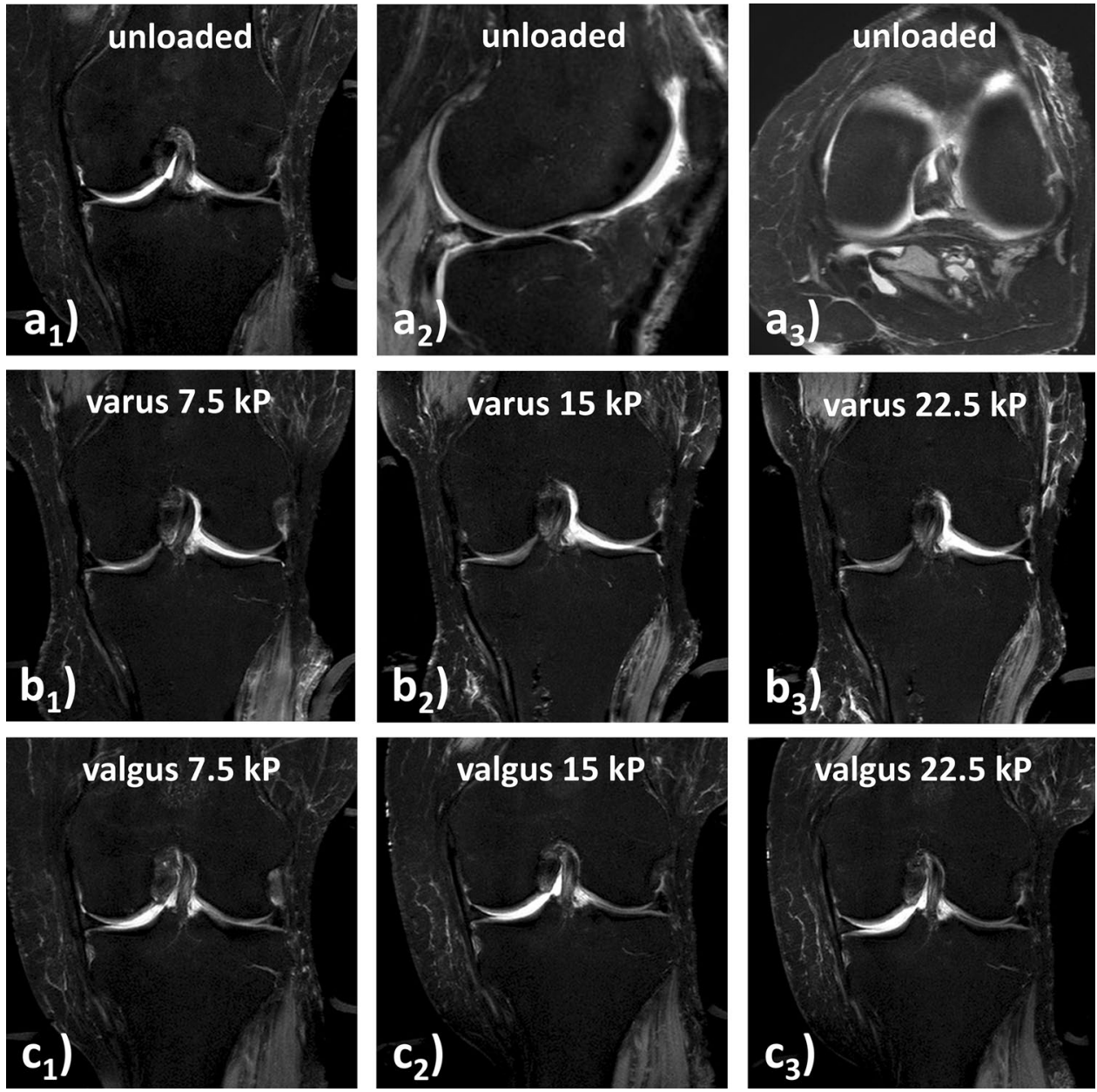

Fig. 3 MR imaging of gradually increasing varus and valgus loading of the human cadaveric knee joint. a MR images in the unloaded configuration (PDW fs) obtained at three orientations, i.e. coronal ( $\mathbf{a}_{1}$, through central weight-bearing region of the femur), sagittal $\left(\mathbf{a}_{2}\right.$, through lateral femorotibial joint), and axial (a $\mathbf{a}_{3}$, through distal femoral condyles). Structurally, the joint was grossly intact. b MR images of the coronal reference plane (as in $\mathbf{a}_{1}$ ) in response to increasing varus loading of $7.5 \mathrm{kPa}\left(\mathbf{b}_{1}\right), 15 \mathrm{kPa}\left(\mathbf{b}_{2}\right)$, and $22.5 \mathrm{kPa}$ $\left(\mathbf{b}_{3}\right)$. Medially, progressive narrowing of the femorotibial articulation

Increasing the loading intensity in the high-loading range, i.e. $15-22.5 \mathrm{kPa}$, produced only smaller-and partially inconsistent-changes in $\mathrm{VC}$ and $\mathrm{ThC}$ as compared to the low-loading range, i.e. unloaded to $15 \mathrm{kPa}$. Changes in $\mathrm{AC}$ were inconsistent and not clearly related to type and intensity of loading.

Overall, analysis of the distinct subregions confirmed the above-mentioned findings (Table 3, Fig. 4). In response to varus loading, largest decreases in ThC of $\mathrm{cMF}$ and MT were determined in the central and internal subregions, while in the remaining subregions [i.e. external, anterior, and posterior (tibial); external (femoral)] changes were consistent and less pronounced. Correspondingly, largest decreases in $\mathrm{ThC}$ in response to valgus loading were found in the central is accompanied by decreasing amounts of interarticular joint fluid; laterally, progressive distention of the femorotibial articulation. $\mathbf{c}$ MR images of the coronal reference plane (as in $\mathbf{a}_{\mathbf{1}}$ and $\mathbf{b}$ in response to increasing valgus loading of $7.5 \mathrm{kPa}\left(\mathbf{c}_{1}\right), 15 \mathrm{kPa}\left(\mathbf{c}_{2}\right)$, and $22.5 \mathrm{kPa}$ $\left(\mathbf{c}_{3}\right)$. While the lateral femorotibial articulation is progressively compressed, the medial femorotibial articulation is gradually distended. Note the silhouettes of the pressure applicator on the medial (b) or lateral (c) aspect of the joint and of the counter-bearings on the lateral (b) and medial (c) aspects

and internal subregions of LT, while for cLF, changes were less consistent. Loading-related decreases in cLF were only found in the external subregion. Closer evaluation of the tibial changes along the anteroposterior dimension revealed that decreases in $\mathrm{ThC}$ tended to be larger in anterior than posterior subregions of MT and LT, in particular at higher loading intensities.

For CT studies, qualitative and quantitative evaluation confirmed the findings above. Figure 5a gives detailed volume renderings in the different loading configurations. In response to varus loading, mean joint space widths (JSWs) of the MFTC decreased from $4.6 \pm 0.6 \mathrm{~mm}\left(\delta_{0}\right)$ to $4.0 \pm$ $0.6 \mathrm{~mm}\left(\delta_{\text {var } 1}\right), 3.5 \pm 0.8 \mathrm{~mm}\left(\delta_{\text {var } 2}\right)$, and $3.4 \pm 0.6 \mathrm{~mm}$ $\left(\delta_{\mathrm{var} 3}\right)$. Correspondingly, in response to valgus loading, 
Table 2 Articular cartilage morphometric measures of the medial and lateral femorotibial joint compartments of a human cadaveric knee joint as a function of increasing varus-valgus loading intensity, i.e. unloaded and after $7.5 \mathrm{kPa}, 15 \mathrm{kPa}$, and $22.5 \mathrm{kPa}$ varus-valgus loading

\begin{tabular}{|c|c|c|c|c|c|c|c|}
\hline & Unloaded & $7.5 \mathrm{kPa}$ varus & $15 \mathrm{kPa}$ varus & $22.5 \mathrm{kPa}$ varus & $7.5 \mathrm{kPa}$ valgus & $15 \mathrm{kPa}$ valgus & $22.5 \mathrm{kPa}$ valgus \\
\hline \multicolumn{8}{|c|}{ Medial compartment } \\
\hline \multicolumn{8}{|l|}{ Tibia } \\
\hline $\mathrm{VC}\left(\mathrm{mm}^{3}\right)$ & 1608.8 & $1534.7(-4.6)$ & $1507.2(-6.3)$ & $1500.0(-6.8)$ & $1546.2(-3.9)$ & $1592.2(-1.0)$ & $1614.8(0.4)$ \\
\hline $\mathrm{ThC}(\mathrm{mm})$ & $1.509 \pm 0.604$ & $\begin{array}{l}1.458 \pm 0.564 \\
\quad(-3.4)\end{array}$ & $\begin{array}{l}1.423 \pm 0.553 \\
(-5.7)\end{array}$ & $\begin{array}{l}1.416 \pm 0.535 \\
\quad(-6.2)\end{array}$ & $\begin{array}{l}1.475 \pm 0.586 \\
(-2.3)\end{array}$ & $\begin{array}{l}1.492 \pm 0.586 \\
(-1.1)\end{array}$ & $\begin{array}{l}1.514 \pm 0.587 \\
(0.3)\end{array}$ \\
\hline $\mathrm{AC}\left(\mathrm{cm}^{2}\right)$ & 10.86 & $10.70(-1.5)$ & $10.77(-0.8)$ & $10.79(-0.6)$ & $10.68(-1.7)$ & $10.86(0)$ & $10.88(0.2)$ \\
\hline \multicolumn{8}{|l|}{ Femur } \\
\hline $\mathrm{VC}\left(\mathrm{mm}^{3}\right)$ & 921.5 & $868.8(-5.7)$ & $827.0(-10.3)$ & $819.8(-11.0)$ & $941.4(2.2)$ & $893.6(-3.0)$ & $917.1(-0.5)$ \\
\hline $\mathrm{ThC}(\mathrm{mm})$ & $1.727 \pm 0.523$ & $\begin{array}{l}1.631 \pm 0.507 \\
(-5.6)\end{array}$ & $\begin{array}{l}1.566 \pm 0.491 \\
(-9.3)\end{array}$ & $\begin{array}{l}1.558 \pm 0.498 \\
(-9.8)\end{array}$ & $\begin{array}{l}1.744 \pm 0.533 \\
\quad(1.0)\end{array}$ & $\begin{array}{l}1.674 \pm 0.514 \\
(-3.1)\end{array}$ & $\begin{array}{l}1.724 \pm 0.537 \\
(-0.2)\end{array}$ \\
\hline $\mathrm{AC}\left(\mathrm{cm}^{2}\right)$ & 5.65 & $5.62(-0.5)$ & $5.55(-1.8)$ & $5.55(-1.8)$ & $5.71(1.1)$ & $5.62(-0.5)$ & $5.63(-0.4)$ \\
\hline \multicolumn{8}{|c|}{ Lateral compartment } \\
\hline \multicolumn{8}{|l|}{ Tibia } \\
\hline $\mathrm{VC}\left(\mathrm{mm}^{3}\right)$ & 1547.3 & $1496.8(-3.3)$ & $1502.6(-2.9)$ & $1517.2(-1.9)$ & $1482.7(-4.2)$ & $1445.4(-6.6)$ & $1471.3(-4.9)$ \\
\hline ThC (mm) & $1.760 \pm 0.841$ & $\begin{array}{l}1.712 \pm 0.813 \\
(-2.7)\end{array}$ & $\begin{array}{l}1.696 \pm 0.810 \\
(-3.6)\end{array}$ & $\begin{array}{l}1.717 \pm 0.854 \\
(-2.4)\end{array}$ & $\begin{array}{l}1.680 \pm 0.791 \\
(-4.5)\end{array}$ & $\begin{array}{l}1.644 \pm 0.777 \\
(-6.6)\end{array}$ & $\begin{array}{l}1.646 \pm 0.753 \\
(-6.5)\end{array}$ \\
\hline $\mathrm{AC}\left(\mathrm{cm}^{2}\right)$ & 9.04 & $8.95(-1.0)$ & $9.11(0.8)$ & $9.05(0.1)$ & $9.09(0.6)$ & $8.99(-0.6)$ & $9.18(1.5)$ \\
\hline \multicolumn{8}{|l|}{ Femur } \\
\hline $\mathrm{VC}\left(\mathrm{mm}^{3}\right)$ & 1013.1 & $1083.8(7.0)$ & $1089.0(7.5)$ & $1079.8(6.6)$ & $1052.8(3.9)$ & $986.2(-2.7)$ & $1009.2(-0.4)$ \\
\hline ThC (mm) & $1.637 \pm 0.545$ & $\begin{array}{l}1.750 \pm 0.549 \\
\quad(6.9)\end{array}$ & $\begin{array}{l}1.744 \pm 0.553 \\
\quad(6.5)\end{array}$ & $\begin{array}{l}1.735 \pm 0.557 \\
\quad(6.0)\end{array}$ & $\begin{array}{l}1.697 \pm 0.558 \\
\quad(3.7)\end{array}$ & $\begin{array}{l}1.591 \pm 0.533 \\
\quad(-2.8)\end{array}$ & $\begin{array}{l}1.622 \pm 0.556 \\
(-0.9)\end{array}$ \\
\hline $\mathrm{AC}\left(\mathrm{cm}^{2}\right)$ & 6.52 & $6.55(0.5)$ & $6.61(1.4)$ & $6.58(0.9)$ & $6.56(0.6)$ & $6.55(0.5)$ & $6.58(0.9)$ \\
\hline
\end{tabular}

Data are presented as mean value $(\mathrm{VC}$ and $\mathrm{AC}) \pm$ standard deviation $(\mathrm{ThC})$ and [percentage change versus the unloaded configuration (\%)]. Morphometric measures were derived from manually segmented high-resolution WATSc sequences

$V C$ cartilage volume $\left(\mathrm{mm}^{3}\right), T h C$ cartilage thickness $(\mathrm{mm}), A C$ cartilage surface area $\left(\mathrm{cm}^{2}\right)$

mean JSWs of the LFTC decreased from $7.2 \pm 1.5 \mathrm{~mm}$ $\left(\delta_{0}\right)$ to $5.2 \pm 0.6 \mathrm{~mm}\left(\delta_{\mathrm{vlg} 1}\right), 4.8 \pm 0.6 \mathrm{~mm}\left(\delta_{\mathrm{vlg} 2}\right)$, and 4.4 $\pm 0.9 \mathrm{~mm}\left(\delta_{\mathrm{vlg} 3}\right)$. For the unloaded joint compartments, i.e. the LFTC under varus loading and the MFTC under valgus loading, gradually distended JSWs were found, e.g. LFTC under varus loading: $7.2 \pm 1.5 \mathrm{~mm}\left(\delta_{0}\right), 9.1 \pm 2.0$ $\mathrm{mm}\left(\delta_{\mathrm{var} 1}\right), 10.5 \pm 0.9 \mathrm{~mm}\left(\delta_{\mathrm{var} 2}\right), 11.5 \pm 0.3 \mathrm{~mm}\left(\delta_{\mathrm{var} 3}\right)$; mean JSWs of the medial femorotibial compartment under valgus loading: $4.6 \pm 0.6 \mathrm{~mm}\left(\delta_{0}\right), 7.3 \pm 2.1 \mathrm{~mm}\left(\delta_{\mathrm{vlg} 1}\right)$, $8.3 \pm 2.6 \mathrm{~mm}\left(\delta_{\mathrm{vlg} 2}\right), 8.7 \pm 2.7 \mathrm{~mm}\left(\delta_{\mathrm{vlg} 3}\right)$.

For radiography, similar observations were made (Fig. 5b). Mean JSWs of the MFTC decreased from 4.5 $\pm 0.8 \mathrm{~mm}\left(\delta_{0}\right)$ to $3.7 \pm 1.0 \mathrm{~mm}\left(\delta_{\mathrm{var} 1}\right)$, and $3.0 \pm 0.6$ $\mathrm{mm}\left(\delta_{\mathrm{var} 2}\right)$ in response to varus loading. Correspondingly, mean JSWs of the LFTC decreased from $6.5 \pm 0.8 \mathrm{~mm}$ $\left(\delta_{0}\right)$ to $5.1 \pm 0.1 \mathrm{~mm}\left(\delta_{\mathrm{vlg} 1}\right)$, and $4.6 \pm 0.2 \mathrm{~mm}\left(\delta_{\mathrm{vlg} 2}\right)$ in response to valgus loading.

Flexion of the knee joint gradually increased in response to loading, from $20^{\circ}\left(\delta_{0}\right)$ to $29^{\circ}\left(\delta_{\mathrm{var} 1}\right), 45^{\circ}\left(\delta_{\mathrm{var} 2}\right)$, and $48^{\circ}$ $\left(\delta_{\mathrm{var} 3}\right)$ as well as to $23^{\circ}\left(\delta_{\mathrm{vlg} 1}\right), 25^{\circ}\left(\delta_{\mathrm{vlg} 2}\right)$, and $28^{\circ}\left(\delta_{\mathrm{vlg} 3}\right)$. Similarly, rotation of the knee joint gradually increased, too, from $13^{\circ}$ external rotation $\left(\delta_{0}\right)$ to $17^{\circ}\left(\delta_{\text {var } 1}\right), 25^{\circ}$ $\left(\delta_{\mathrm{var} 2}\right)$, and $29^{\circ}\left(\delta_{\mathrm{var} 3}\right)$, while it remained unchanged in response to increasing valgus loading.

Biomechanical reference evaluation of the sampled cartilage areas revealed considerable variability across the knee joint. Instantaneous Young's modulus was quantified as 1.11 MPa (MF), 0.34 MPa (LF), 1.88 MPa (MT), and $1.92 \mathrm{MPa}$ (LT). Figure 6 gives detailed results of the histological reference evaluation.

\section{Discussion}

The most important findings of the present study are that (1) VVL of the human knee joint induces efficient compartmental compression, thereby providing an alternative loading mechanism for functional joint assessment and that (2) intratissue adaptations in response to VVL were reliably detected using high-resolution morphological MRI techniques.

Based on the developed MRI-compatible VVL device, pressure may be actuated along the joint line in exactly defined varus or valgus configurations as controlled by pressure. The relation of set pressure levels and resultant forces 
Table 3 Mean cartilage thickness of the medial and lateral femorotibial joint compartment subregions

Unloaded $7.5 \mathrm{kPa}$ varus $15 \mathrm{kPa}$ varus $\quad 22.5 \mathrm{kPa}$ varus $\quad 7.5 \mathrm{kPa}$ valgus $\quad 15 \mathrm{kPa}$ valgus $22.5 \mathrm{kPa}$ valgus

\begin{tabular}{|c|c|c|c|c|c|c|c|}
\hline \multicolumn{8}{|l|}{ Medial compartment } \\
\hline \multicolumn{8}{|l|}{ Tibia } \\
\hline Central subregion of MT & 2.02 & $1.97(-2.5)$ & $1.89(-6.4)$ & $1.88(-6.9)$ & $1.95(-3.5)$ & $2.00(-1.0)$ & $2.03(0.5)$ \\
\hline External subregion of MT & 1.27 & $1.25(-1.6)$ & $1.21(-4.7)$ & $1.22(-3.9)$ & $1.26(-0.8)$ & $1.25(-1.6)$ & $1.27(0)$ \\
\hline Internal subregion of MT & 1.55 & $1.48(-4.5)$ & $1.42(-8.4)$ & $1.42(-8.4)$ & $1.57(1.3)$ & $1.55(0)$ & $1.59(2.6)$ \\
\hline Anterior subregion of MT & 1.45 & $1.36(-6.2)$ & $1.36(-6.2)$ & $1.38(-4.8)$ & $1.37(-5.5)$ & $1.43(-1.4)$ & $1.35(-6.9)$ \\
\hline Posterior subregion of MT & 1.29 & $1.26(-2.3)$ & $1.25(-3.1)$ & $1.21(-6.2)$ & $1.28(-0.8)$ & $1.27(-1.6)$ & $1.38(7.0)$ \\
\hline \multicolumn{8}{|l|}{ Femur } \\
\hline Central subregion of cMF & 2.12 & $2.03(-4.2)$ & $1.94(-8.5)$ & $1.94(-8.5)$ & $2.16(1.9)$ & $2.06(-2.8)$ & $2.13(0.5)$ \\
\hline External subregion of $\mathrm{cMF}$ & 1.58 & $1.50(-5.1)$ & $1.45(-8.2)$ & $1.43(-9.5)$ & $1.58(0)$ & $1.51(-4.4)$ & $1.57(-0.6)$ \\
\hline Internal subregion of $\mathrm{cMF}$ & 1.52 & $1.41(-7.2)$ & $1.34(-11.8)$ & $1.34(-11.8)$ & $1.53(0.7)$ & $1.48(-2.6)$ & $1.51(-0.7)$ \\
\hline \multicolumn{8}{|l|}{ Lateral compartment } \\
\hline \multicolumn{8}{|l|}{ Tibia } \\
\hline Central subregion of LT & 2.68 & $2.59(-3.4)$ & $2.55(-4.9)$ & $2.63(-1.9)$ & $2.51(-6.3)$ & $2.47(-7.8)$ & $2.44(-9.0)$ \\
\hline External subregion of LT & 1.41 & $1.29(-8.5)$ & $1.29(-8.5)$ & $1.29(-8.5)$ & $1.38(-2.1)$ & $1.33(-5.7)$ & $1.35(-4.3)$ \\
\hline Internal subregion of LT & 1.95 & $1.87(-4.1)$ & $1.90(-2.6)$ & $1.95(0)$ & $1.84(-5.6)$ & $1.82(-6.7)$ & $1.78(-8.7)$ \\
\hline Anterior subregion of LT & 1.51 & $1.52(0.8)$ & $1.51(0)$ & $1.51(0)$ & $1.46(-3.3)$ & $1.42(-6.0)$ & $1.45(-4.0)$ \\
\hline Posterior subregion of LT & 1.38 & $1.36(-1.4)$ & $1.31(-5.1)$ & $1.30(-5.8)$ & $1.31(-5.1)$ & $1.28(-7.2)$ & $1.30(-5.8)$ \\
\hline \multicolumn{8}{|l|}{ Femur } \\
\hline Central subregion of cLF & 1.97 & $2.05(4.1)$ & $2.08(5.6)$ & $2.07(5.1)$ & $2.04(3.6)$ & $1.91(-3.0)$ & $1.96(-0.5)$ \\
\hline External subregion of cLF & 1.38 & $1.50(8.7)$ & $1.49(8.0)$ & $1.49(8.0)$ & $1.40(1.4)$ & $1.31(-5.1)$ & $1.29(-6.5)$ \\
\hline Internal subregion of cLF & 1.59 & $1.72(8.2)$ & $1.69(6.3)$ & $1.68(5.7)$ & $1.67(5.0)$ & $1.57(-1.3)$ & $1.64(3.1)$ \\
\hline
\end{tabular}

Cartilage thickness was quantified in a human cadaveric knee joint subjected to increasing varus-valgus loading. Data are given as mean thickness (mm) [percentage change versus unloaded configuration (\%)]. See Table 2 for additional details

$M T$ medial tibia, $c M F$ central medial femur, $L T$ lateral tibia, $c L F$ central lateral femur

generated at the padded actuator was close-to-perfectly linear. Most likely because of unavoidable friction and leakage within the pressurized infrastructure, i.e. the pressure lines and the pneumatic mechanism, this association was not perfectly linear. Longitudinal force measurements confirmed that the pneumatic mechanism maintains constant forces over extended time periods, i.e. at least $30 \mathrm{~min}$, which is a prerequisite for combining loading with advanced MR imaging techniques that are time-consuming and necessitate constant loading conditions to reduce movement artefacts. Even though reference pressure mappings indicated effective pressurization of the MFTC and LFTC, VVL induced considerably lower intraarticular pressures than compressive axial loading along the joint's mechanical axis with $\geq 50 \%$ body weight (thoroughly reviewed in [6]). Of course, forces in response to VVL were substantially lower because of the principally different loading mechanisms. Mechanistically, when applying loading along the joint line while keeping both the distal femur and proximal tibia fixed, the knee joint centre becomes the fulcrum (i.e. centre of rotation) in the presence of such bending moments. Naturally, this induces inherently different distributions of pressure across the joint. Unfortunately, literature data on the biomechanics of VVL in general and on intraarticular pressurization in particular are scarce. While a solid body of scientific evidence demonstrated that forces are increased in the MFTC in varus (mal-) aligned knees and in the LFTC in valgus (mal-)aligned knees [28, 36-39], direct in vivo measurements of stress and strain within the knee joint are challenging, which may explain the paucity of available data. Current knowledge is primarily based on human cadaveric knee joint studies, e.g. [28], instrumented implants during or after total knee arthroplasty (TKA) [40-42], or computational models [37, 43]. When axially loading human cadaveric knee joints at $1000 \mathrm{~N}$ and different loading axes, Agneskirchner et al. found strong correlations between the degree of varus or valgus and the distribution of mean and peak contact pressures at the MFTC and LFTC [28]. Even though the topographic pressure distribution was not systematically investigated in their study, the central and inner compartmental joint surface areas were most pressurized, while the peripheral areas experienced less stress and strain. These observations were in line with earlier studies that assessed the pressure distribution in the knee during TKA and found primary involvement of the inner and central areas of the MFTC and LFTC in VVL [40, 44]. Our morphometric cartilage measures confirmed this 


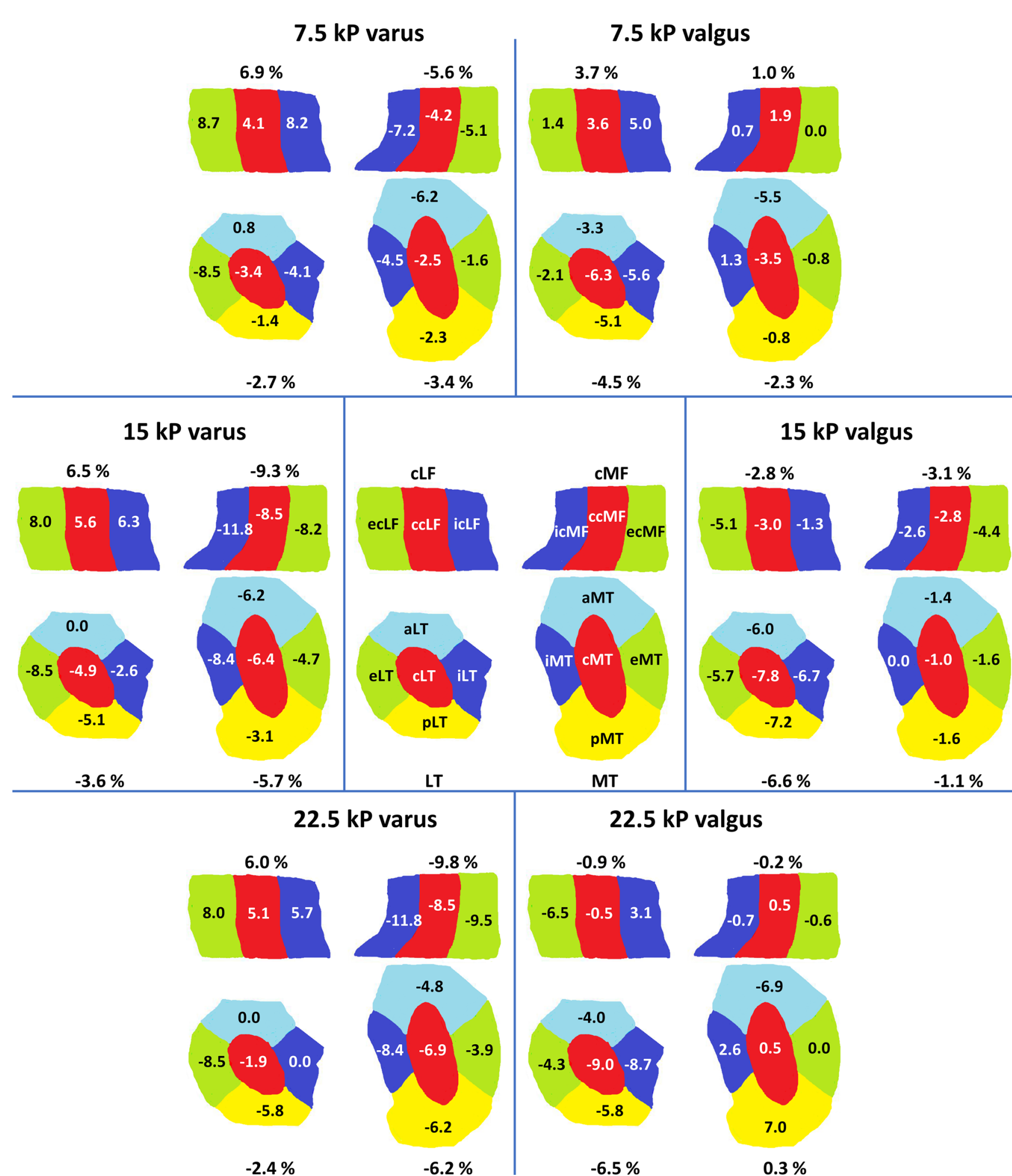

Fig. 4 Projections to demonstrate relative changes in $\mathrm{ThC}$ in the distinct femoral and tibial regions and subregions as a function of joint configuration, i.e. loading intensity (at $7.5 \mathrm{kPa}, 15 \mathrm{kPa}$, and $22.5 \mathrm{kPa}$ ) and direction (varus and valgus). The central part of the medial (cMF) and lateral femur (cLF) were partitioned into the central (c), external (e), and internal subregions (i), while the medial

(MT) and lateral tibia (LT) were partitioned into the central (c), external (e), internal (i), anterior (a), and posterior subregions (p). Relative changes in $\mathrm{ThC}$ and in the cartilage plate of the region and subregion as compared to the unloaded reference configuration (\%). Visualization inspired by [35] 


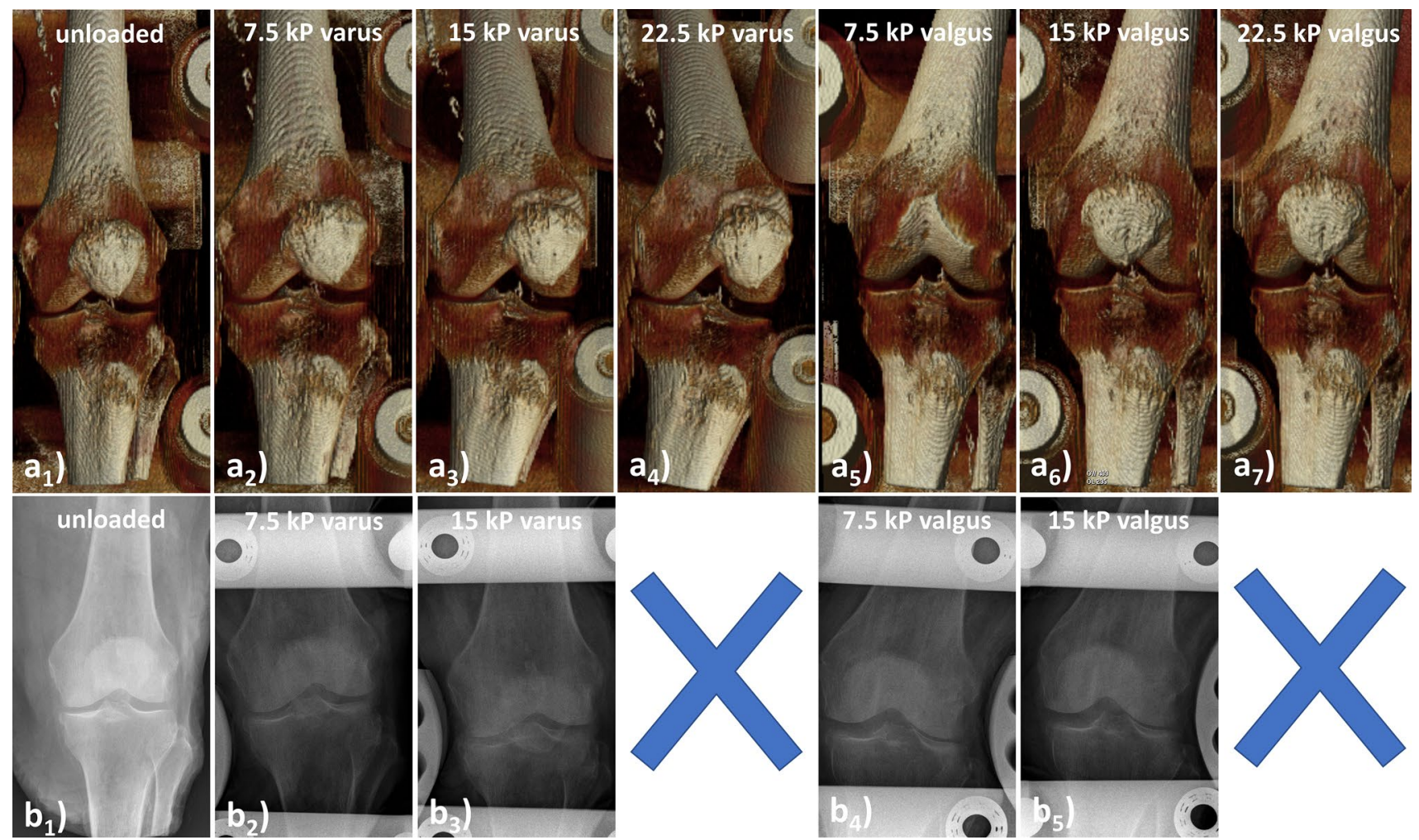

Fig. 5 CT volume renderings (a) and radiographs (b) of the human cadaveric knee joint subjected to varus and valgus loading. Shaded volume renderings (a) were obtained in the unloaded configuration $\left(\mathbf{a}_{1}\right)$, at $7.5 \mathrm{kPa}$ varus $\left(\mathbf{a}_{2}\right), 15 \mathrm{kPa}$ varus $\left(\mathbf{a}_{3}\right), 22.5 \mathrm{kPa}$ varus $\left(\mathbf{a}_{4}\right)$, $7.5 \mathrm{kPa}$ valgus $\left(\mathbf{a}_{5}\right), 15 \mathrm{kPa}$ valgus $\left(\mathbf{a}_{\mathbf{6}}\right)$, and $22.5 \mathrm{kPa}$ valgus $\left(\mathbf{a}_{7}\right)$. Because of variable flexion and rotation, the volume-of-interest was centered on the knee as well as rotated and angulated to allow for unobstructed visualization of the joint space. Due to force restrictions of the stress radiography device anteroposterior radiographs could not be obtained at $22.5 \mathrm{kPa}$ (indicated by blue crosses), but only in the unloaded configuration $\left(\mathbf{b}_{1}\right)$, at $7.5 \mathrm{kPa}$ varus $\left(\mathbf{b}_{2}\right), 15 \mathrm{kPa}$ varus $\left(\mathbf{b}_{3}\right)$, $7.5 \mathrm{kPa}$ valgus $\left(\mathbf{b}_{4}\right)$, and $15 \mathrm{kPa}$ valgus $\left(\mathbf{b}_{5}\right)$
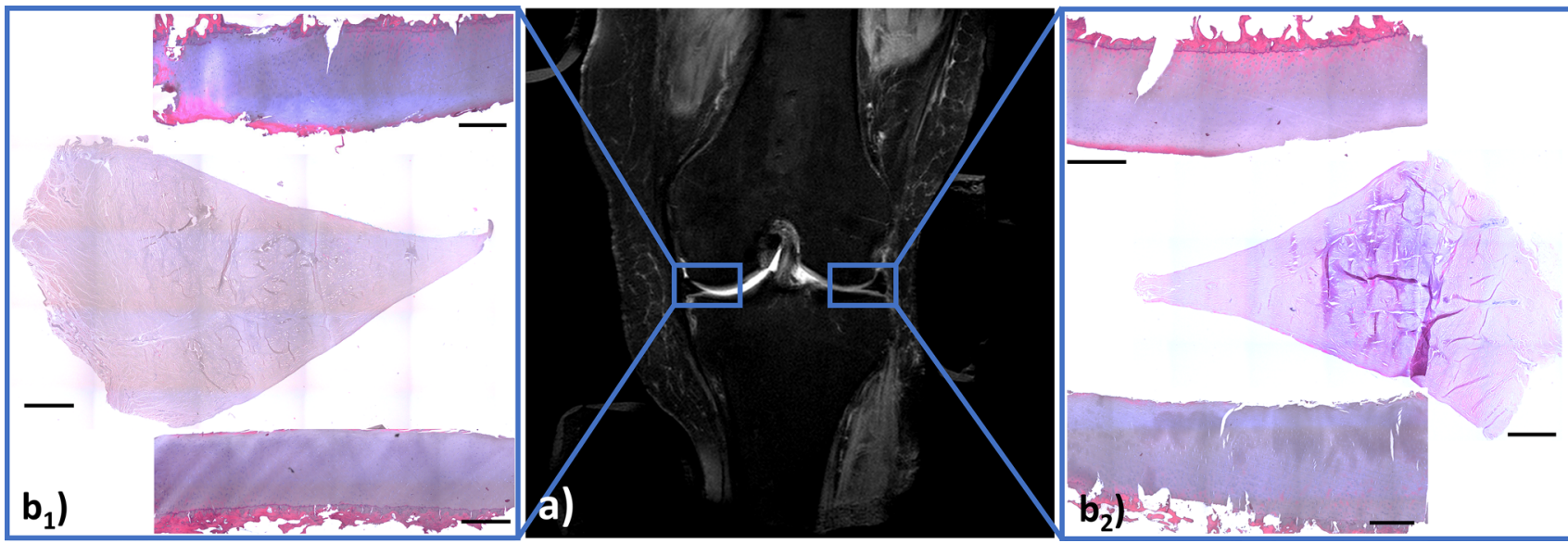

Fig. 6 Synopsis of histological reference analysis. Coronal reference MR image [PDw-fs (a)] of the human cadaveric knee joint in the unloaded configuration. Light blue boxes indicate the site of cartilage and meniscus harvesting for subsequent histological analysis of the medial $\left(\mathbf{b}_{1}\right)$ and lateral $\left(\mathbf{b}_{\mathbf{2}}\right)$ femorotibial joint compartments. Sampled femoral and tibial cartilage regions are shown at the top and bottom of the boxes, while the medial and lateral meniscus samples are positioned in-between. Cartilage samples were grossly intact with slight signs of early degeneration, i.e. focal surface disintegration, hypercel- lularity, and superficial proteoglycan de-staining. Medial femoral cartilage, however, displayed moderate-to-severe signs of degeneration, i.e. cellular cloning, clefting, and incipient tissue loss. Similarly, the lateral meniscus displayed severe signs of degeneration such as fraying of the apex, focal matrix disorganization, fibrocartilaginous separation, and strong proteoglycan staining, while the medial meniscus was structurally intact. Hematoxylin-eosin staining. Bars in histological sections are scaled to $1 \mathrm{~mm}$. Note that the light blue boxes are not to scale 
spatial heterogeneity in pressurization across the knee joint in response to VVL. Loading-induced decreases in VC and $\mathrm{ThC}$ are indicative of effective pressurization of the MFTC in varus (and of the LFTC in valgus) and even though the compartments were loaded in their entirety, changes in $\mathrm{VC}$ and $\mathrm{ThC}$ were most pronounced in the central and inner subregions, both for the femur and the tibia, which confirms these earlier in vitro and in vivo data. In our study, further subregional analysis revealed that decreases in $\mathrm{ThC}$ wereby trend-larger in the posterior than anterior subregions of the tibia, especially at higher loading intensities. This finding may be explained by the concurrently increasing joint flexion angles as a result of loading, which not only decrease the contact areas and shift them in the posterior direction [45], but also increase the magnitude of cartilage contact deformation [46]. Discrepancies in study protocols, research questions and methodology (including loading regimes, measurement setups and overall framework conditions) as well as anatomy limit comparability of these findings to the conventional biomechanical literature.

In terms of cartilage deformation, our findings are well in line with previous stress MRI studies. Subjecting a healthy volunteer's knee joint to a compressive axial load of $50 \%$ body weight, Subburaj et al. determined decreases in ThC of $0.074 \mathrm{~mm}$ (MFC), $0.003 \mathrm{~mm}$ (LFC), $0.071 \mathrm{~mm}$ (MT), and $0.061 \mathrm{~mm}$ (LT) based on mean (unloaded) ThC values of $1.42 \mathrm{~mm}, 1.49 \mathrm{~mm}, 1.35 \mathrm{~mm}$ and $1.71 \mathrm{~mm}$, respectively [5]. Amounting to relative changes that ranged from -1.0 to $-6.9 \%$, the range of loading-induced changes reported in their study is comparable to our study. Interestingly, they also found cartilage deformation to be considerably larger in the MFTC than the LFTC, which was mainly due to the fact that the cartilage of the LF underwent hardly any changes. In contrast, loading induced largely consistent decreases in the cartilage thickness of the MF, MT and LT. In line with earlier in vivo studies reporting similar findings for axial loading [46, 47], our study, too, confirmed these findings. Consequently, effective cartilage pressurization when loaded along the joint axis (i.e. axially) and perpendicular to it (i.e. varus-valgus) seems similar and again confirms the mechanistic equivalence of VVL as compared to compressive axial loading, while keeping logistical and infrastructural demands manageable.

While stress radiography of the knee has been performed with variable loading intensities ranging from 3 to $30 \mathrm{kPa}$ [21], our results indicate that load responsiveness of cartilage may be the greatest at loads of up to $15 \mathrm{kPa}$. Higher loading intensities (of up to $22 \mathrm{kPa}$ ) produced smaller and less consistent intra-tissue adaptations and may increase the risk of iatrogenic complications. It remains speculative why we could not find a linear relationship between loading intensity and relative changes in ThC for high-loading intensities. Possible explanations involve the more focal compartmental loading with more severe misalignment [28], possible force dissipation due to secondary adaptive flexion and external rotation, and increasingly relevant static stabilizers in unphysiological joint configurations [48]. For practical considerations, VVL should therefore be realized within the recommended range of $0-15 \mathrm{kPa}$ [21]. MRI measurements and subsequent morphometric quantifications were performed in the order 1-7 as detailed above. Even though an equilibration period of $5 \mathrm{~min}$ was obeyed after each change in pressure level, we cannot exclude the possibility that the morphometric measures are also affected by the measurement order. Cartilage relaxation is related to loading intensity with longer relaxation (and ongoing intratissue adaptations) observed for higher-intensity loading $[32,33]$ and full ultrastructural recovery may necessitate extended relaxation periods of up to several hours $[49,50]$. Hence, additional studies need to evaluate if (1) the equilibration period is justified by striking a sensible balance between additional magnet time and sufficient tissue relaxation and (2) the measurement order affects the morphometric measurements.

Our study and others [5, 46, 47] indicate that valgus loading-induced changes in the cartilage of the LT are undulating and inconsistent. Possible explanations involve knee joint-specific anatomic and biomechanical aspects. For once, due to its concave geometry, the articular surface of the MT affords higher congruity with the MF condyle, more extensive femorotibial articulation, and-consecutivelyconsistent cartilage straining and deformation $[5,45,51]$. In contrast, the articular surface of the LT is convex, which decreases the area of articulation [51], and may be the reason for the inconsistent subregional cartilage deformation patterns as loads are borne in a more focal than areal manner. For another, cartilage deformation is significantly larger in the MFTC than the LFTC at higher joint flexion angles, in particular between $30^{\circ}$ and $60^{\circ}$ (as in our study) [46].

Whenever absolute cartilage deformation is quantified, the degree of pre-existent degeneration needs to be considered as degenerative cartilage is more compliant [34, 52] which considerably affects loading-induced changes in morphometric measures. Earlier studies demonstrated substantially higher variability in loading-induced changes in $\mathrm{OA}$ versus non-OA [5]. Against this background, the definition of the physiological response to loading hinges on a sound reference standard that is certainly easier to realize in ex vivo studies. Consequently, we performed histological and conventional biomechanical referencing of the (previously loaded) sampled cartilage regions. Except for the MF that displayed moderate-to-severe signs of histological degeneration, sampled cartilage areas displayed only slightto-moderate degeneration throughout the joint. Although the controversy of aging and its role in OA is ongoing [53], this is not surprising given the body donor's age of 78 years. 
Surprisingly, the medial meniscus was histologically intact, while the lateral meniscus displayed more severe degeneration. Even though the exact relation between cartilage and meniscus integrity (and pathology) remains speculative [54], not just in this very knee and patient, the decisive role of the meniscus in compartmental load transmission and its failure in OA warrants additional investigations for which the present study provides a solid framework.

In our study, morphometric analysis was performed on the basis of a high-resolution WATSc sequence that is commonly applied for cartilage segmentation [25] and was obtained at an in-plane resolution of $0.35 \mathrm{~mm} / \mathrm{pixel}$. Such high-resolution imaging is a prerequisite to detect subtle regional cartilage changes with sufficient precision and accuracy and to use cartilage deformation in terms of changes in ThC and VC as imaging biomarkers of cartilage and joint functionality. While overall, unenhanced CT and radiography indicated similar changes within the joint, these modalities are characterized by distinct disadvantages such as radiation exposure, indirect visualization of soft tissues (unless performed as a direct arthrography), and the inability to assess their compositional, (ultra)structural and functional adaptations. These immanent disadvantages render these modalities ill-suited for functional tissue and joint assessment, in particular in view of the ever-more increasing availability of MRI and its distinct advantages such as non-invasiveness, superior soft tissue contrast, and absence of ionizing radiation.

Our study has a number of limitations. First and foremost, we included only one human knee joint specimen. However, the present study's primary objective was to demonstrate proof of concept for joint functionality assessment based on the validated pressure-controlled VVL device. Of course, future studies investigating larger specimen sizes are necessary to corroborate our findings and to define the physiological response to loading across the joint and its pathological aberrations. Second, we only assessed knee joint functionality within the framework provided by the static stabilizers, i.e. capsule, menisci, and cruciate and collateral ligaments, while the dynamic stabilizers, i.e. muscles, could not be assessed. Hence, when it comes to the in vivo translation of our findings, studies including healthy (non-OA) individuals and OA patients are required to bridge this translational gap. Similarly, once regulatory and medicolegal issues have been solved, this proof-of-concept study has to be followed by a comprehensive feasibility study that includes sufficient numbers of volunteers (without OA or knee pain) and patients (with OA and/or knee pain). Aspects related to the concept's in vivo translation such as patient comfort, joint positioning, stabilization, and fixation, device safety and handleability, convenience of operation as well as measurement validity and reproducibility will then be addressed with the device in clinical operation. Future efforts need to be directed at keeping examination times as short as possible, possibly by including abbreviated MRI protocols [55], and loading as low as possible by balancing (still effective) loading intensity against (functionally meaningful) joint and tissue changes. In particular, switching the direction of loading, e.g. from varus to valgus in the same knee, necessarily involves repositioning of the joint, coils and/or principal device components, which is not only impractical, but also means additional examination time. Third, when loaded, the knee joint underwent substantial flexion and-to a lesser extent-rotation, in particular in the varus configuration, which is due to the nonconstrained loading setup. For the sake of standardization of loading, joint motion in response to loading needs to be better controlled, for example by using more confining mounting supports. Yet, any additional mechanical confinement needs to be balanced against the loading-induced adjustments and adaptations of the joint. Fourth, we only assessed morphometric measures such as ThC and VC, while we did apply more advanced MRI techniques such as compositional sequences. By application of $\mathrm{T} 2$ or $\mathrm{T} 1 \rho$ mapping, further inferences on cartilage (ultra)structure and composition (beyond mere morphology) and their changes in response to loading may be made. Fifth, biomechanical reference evaluation using pressure-sensitive sensors may only provide rough estimates of actual pressurization as this evaluation was performed after arthrotomy, preparation, and partial transection, thereby altering the joint's overall soft tissue balance, mechano-functional properties, and effectual load transmission.

In conclusion, the MRI-compatible pressure-controlled VVL device provides a new and innovative way of assessing knee joint functionality based on pressurization of the MFTC and LFTC. In this proof-of-concept study, effective compartmental pressurization is reflected by distinct loading-induced patterns of subregional cartilage deformation and indicates the methodology's potential application in basic, translational and clinical research questions. Once substantiated by more refined imaging, biomechanical, and compositional cross-references, this approach may improve handleability, decrease logistical demands, and provide a safe and powerful alternative technique for stress MRI in the context of functional joint and tissue assessment.

Acknowledgements This work was supported by the Deutsche Forschungsgemeinschaft (Grant number: NE 2136/3-1); the START Program of the Faculty of Medicine, RWTH Aachen, Germany (Grant number: 691905 and rotation programme). The authors would like to acknowledge the MR image segmentation and computation work provided by Chondrometrics GmbH (Ainring, Germany), the technical assistance in the histological work-up provided by Tim Clarner, Ph.D. (Institute of Neuroanatomy, RWTH Aachen University) and the general assistance provided by Shou Zhang, Ph.D. (Philips, Best, The Netherlands). 
Author contributions Guarantors of integrity of entire study, all authors; study concepts/study design or data acquisition or data analysis/interpretation, all authors; manuscript drafting or manuscript revision for important intellectual content, all authors; approval of final version of submitted manuscript, all authors; literature research, OS, DT, SN; experimental studies, OS, NK, JT, LH, DA, DT, SN; manuscript editing: OS, JS, PS, CK, DT, SN.

Funding Open Access funding enabled and organized by Projekt DEAL. This work was supported by the Deutsche Forschungsgemeinschaft (Grant number: NE 2136/3-1); the START Program of the Faculty of Medicine, RWTH Aachen, Germany (Grant number: 691905 and rotation programme). The sponsors had no role in the study design; in the collection, analysis and interpretation of data; in the writing of the report; and in the decision to submit the manuscript for publication.

\section{Compliance with ethical standards}

Conflict of interest The authors do not have any financial, consulting or personal relationships with other people or organizations to disclose.

Ethics approval Local Institutional Review Board approval by the relevant Ethical Committee (RWTH Aachen University, AZ-EK180/16) has been obtained prior to this study.

Consent to participate and publish Written informed consent by the body donor (including the explicit will to have their body parts used for medical research and its eventual publication) was available at the time of study initiation.

Open Access This article is licensed under a Creative Commons Attribution 4.0 International License, which permits use, sharing, adaptation, distribution and reproduction in any medium or format, as long as you give appropriate credit to the original author(s) and the source, provide a link to the Creative Commons licence, and indicate if changes were made. The images or other third party material in this article are included in the article's Creative Commons licence, unless indicated otherwise in a credit line to the material. If material is not included in the article's Creative Commons licence and your intended use is not permitted by statutory regulation or exceeds the permitted use, you will need to obtain permission directly from the copyright holder. To view a copy of this licence, visit http://creativecommons.org/licenses/by/4.0/.

\section{References}

1. Gold GE, Besier TF, Draper CE, Asakawa DS, Delp SL, Beaupre GS (2004) Weight-bearing MRI of patellofemoral joint cartilage contact area. J Magn Reson Imaging JMRI 20(3):526-530

2. Buchan LL, Zhang H, Konan S, Heaslip I, Ratzlaff CR, Wilson DR (2016) Open-MRI measures of cam intrusion for hips in an anterior impingement position relate to acetabular contact force. J Orthop Res 34(2):205-216

3. Shapiro LM, Gold GE (2012) MRI of weight bearing and movement. Osteoarthr Cartil 20(2):69-78

4. Chung M, Dahabreh IJ, Hadar N, Ratichek SJ, Gaylor JM, Trikalinos TA, Lau J (2011) Emerging MRI technologies for imaging musculoskeletal disorders under loading stress. AHRQ comparative effectiveness technical briefs, No. 7. Agency for Healthcare Research and Quality (US), Rockville (MD)

5. Subburaj K, Souza RB, Stehling C, Wyman BT, Le GraverandGastineau MP, Link TM, Li X, Majumdar S (2012) Association of MR relaxation and cartilage deformation in knee osteoarthritis. J Orthop Res 30(6):919-926

6. Jerban S, Chang EY, Du J (2020) Magnetic resonance imaging (MRI) studies of knee joint under mechanical loading. Magn Reson Imaging 65:27-36

7. Nishii T, Kuroda K, Matsuoka Y, Sahara T, Yoshikawa H (2008) Change in knee cartilage $\mathrm{T} 2$ in response to mechanical loading. $\mathrm{J}$ Magn Reson Imaging JMRI 28(1):175-180

8. Cotofana S, Eckstein F, Wirth W, Souza RB, Li X, Wyman B, Hellio-Le Graverand MP, Link T, Majumdar S (2011) In vivo measures of cartilage deformation: patterns in healthy and osteoarthritic female knees using 3T MR imaging. Eur Radiol 21(6):1127-1135

9. Souza RB, Kumar D, Calixto N, Singh J, Schooler J, Subburaj K, Li X, Link TM, Majumdar S (2014) Response of knee cartilage $\mathrm{T} 1$ rho and $\mathrm{T} 2$ relaxation times to in vivo mechanical loading in individuals with and without knee osteoarthritis. Osteoarthr Cartil 22(10):1367-1376

10. Souza RB, Stehling C, Wyman BT, Hellio Le Graverand MP, Li X, Link TM, Majumdar S (2010) The effects of acute loading on T1rho and T2 relaxation times of tibiofemoral articular cartilage. Osteoarthr Cartil 18(12):1557-1563

11. Wang H, Koff MF, Potter HG, Warren RF, Rodeo SA, Maher SA (2015) An MRI-compatible loading device to assess knee joint cartilage deformation: effect of preloading and inter-test repeatability. J Biomech 48(12):2934-2940

12. Lange T, Knowles BR, Herbst M, Izadpanah K, Zaitsev M (2017) Comparative T2 and T1rho mapping of patellofemoral cartilage under in situ mechanical loading with prospective motion correction. J Magn Reson Imaging JMRI 46(2):452-460

13. Chan DD, Cai L, Butz KD, Trippel SB, Nauman EA, Neu CP (2016) In vivo articular cartilage deformation: noninvasive quantification of intratissue strain during joint contact in the human knee. Sci Rep 6:19220

14. Chen HN, Yang K, Dong QR, Wang Y (2014) Assessment of tibial rotation and meniscal movement using kinematic magnetic resonance imaging. J Orthop Surg Res 9:65

15. Neu CP (2014) Functional imaging in OA: role of imaging in the evaluation of tissue biomechanics. Osteoarthr Cartil 22(10):1349-1359

16. Gibson P, Goodfellow J (1986) Stress radiography in degenerative arthritis of the knee. J Bone Jt Surg Br 68(4):608-609

17. Waldstein W, Schmidt-Braekling T, Perino G, Kasparek MF, Windhager R, Boettner F (2017) Valgus stress radiographs predict lateral-compartment cartilage thickness but not cartilage degeneration in varus osteoarthritis. J Arthroplast 32(3):788-792

18. Eriksson K, Sadr-Azodi O, Singh C, Osti L, Bartlett J (2010) Stress radiography for osteoarthritis of the knee: a new technique. Knee Surg Sports Traumatol Arthrosc 18(10):1356-1359

19. Koppens D, Sørensen OG, Munk S, Rytter S, Larsen SKA, Stilling M, Hansen TB (2019) The lateral joint space width can be measured reliably with Telos valgus stress radiography in medial knee osteoarthritis. Skelet Radiol 48(7):1069-1077

20. Kijowski R, Blankenbaker D, Stanton P, Fine J, De Smet A (2006) Arthroscopic validation of radiographic grading scales of osteoarthritis of the tibiofemoral joint. AJR Am J Roentgenol 187(3):794-799

21. James EW, Williams BT, LaPrade RF (2014) Stress radiography for the diagnosis of knee ligament injuries: a systematic review. Clin Orthop Relat Res 472(9):2644-2657

22. Oliphant TE (2007) Python for scientific computing. Comput Sci Eng 9(3):10-20

23. Rogers AD, Payne JE, Yu JS (2013) Cartilage imaging: a review of current concepts and emerging technologies. Semin Roentgenol. 48(2):148-157. https://doi.org/10.1053/j.ro.2012.11.006 
24. Gold GE, Chen CA, Koo S, Hargreaves BA, Bangerter NK (2009) Recent advances in MRI of articular cartilage. Am J Roentgenol 193(3):628-638

25. Eckstein F, Guermazi A, Gold G, Duryea J, Le Graverand M-PH, Wirth W, Miller C (2014) Imaging of cartilage and bone: promises and pitfalls in clinical trials of osteoarthritis. Osteoarthr Cartil 22(10):1516-1532

26. Hochberg MC, Guermazi A, Guehring H, Aydemir A, Wax S, Fleuranceau-Morel P, Reinstrup Bihlet A, Byrjalsen I, Ragnar Andersen J, Eckstein F (2019) Effect of intra-articular sprifermin vs placebo on femorotibial joint cartilage thickness in patients with osteoarthritis: the FORWARD randomized clinical trial. JAMA 322(14):1360-1370

27. Eckstein F, Maschek S, Roemer FW, Duda GN, Sharma L, Wirth W (2019) Cartilage loss in radiographically normal knees depends on radiographic status of the contralateral knee-data from the osteoarthritis initiative. Osteoarthr Cartil 27(2):273-277

28. Agneskirchner JD, Hurschler C, Wrann CD, Lobenhoffer P (2007) The effects of valgus medial opening wedge high tibial osteotomy on articular cartilage pressure of the knee: a biomechanical study. Arthroscopy 23(8):852-861

29. Suero EM, Hawi N, Westphal R, Sabbagh Y, Citak M, Wahl FM, Krettek C, Liodakis E (2015) The effect of distal tibial rotation during high tibial osteotomy on the contact pressures in the knee and ankle joints. Knee Surg Sports Traumatol Arthrosc. https:// doi.org/10.1007/s00167-015-3553-4

30. Nebelung S, Post M, Knobe M, Tingart M, Emans P, Thuring J, Kuhl C, Truhn D (2019) Detection of early-stage degeneration in human articular cartilage by multiparametric MR imaging mapping of tissue functionality. Sci Rep 9(1):5895

31. Truhn D, Sondern B, Oehrl S, Tingart M, Knobe M, Merhof D, Kuhl C, Thuring J, Nebelung S (2019) Differentiation of human cartilage degeneration by functional MRI mapping-an ex vivo study. Eur Radiol 29(12):6671-6681

32. Nebelung S, Post M, Knobe M, Shah D, Schleich C, Hitpass L, Kuhl C, Thuring J, Truhn D (2019) Human articular cartilage mechanosensitivity is related to histological degeneration-a functional MRI study. Osteoarthr Cartil 27(11):1711-1720

33. Nebelung S, Sondern B, Jahr H, Tingart M, Knobe M, Thuring J, Kuhl C, Truhn D (2018) Non-invasive T1rho mapping of the human cartilage response to loading and unloading. Osteoarthr Cartil 26(2):236-244

34. Nebelung S, Sondern B, Oehrl S, Tingart M, Rath B, Pufe T, Raith S, Fischer H, Kuhl C, Jahr H, Truhn D (2017) Functional MR imaging mapping of human articular cartilage response to loading. Radiology 282(2):464-474

35. Wirth W, Maschek S, Eckstein F (2017) Sex-and age-dependence of region-and layer-specific knee cartilage composition (spinspin-relaxation time) in healthy reference subjects. Ann Anat (Anatomischer Anzeiger) 210:1-8

36. Sharma L, Chmiel JS, Almagor O, Felson D, Guermazi A, Roemer F, Lewis CE, Segal N, Torner J, Cooke TDV, Hietpas J, Lynch J, Nevitt M (2013) The role of varus and valgus alignment in the initial development of knee cartilage damage by MRI: the MOST study. Ann Rheum Dis 72(2):235-240

37. Yang NH, Canavan PK, Nayeb-Hashemi H (2010) The effect of the frontal plane tibiofemoral angle and varus knee moment on the contact stress and strain at the knee cartilage. J Appl Biomech 26(4):432

38. Tanamas S, Hanna FS, Cicuttini FM, Wluka AE, Berry P, Urquhart DM (2009) Does knee malalignment increase the risk of development and progression of knee osteoarthritis? A systematic review. Arthritis Rheum 61(4):459-467

39. Felson DT, Niu J, Gross KD, Englund M, Sharma L, Cooke TD, Guermazi A, Roemer FW, Segal N, Goggins JM, Lewis CE, Eaton
C, Nevitt MC (2013) Valgus malalignment is a risk factor for lateral knee osteoarthritis incidence and progression: findings from the multicenter osteoarthritis study and the osteoarthritis initiative. Arthritis Rheum 65(2):355-362

40. Takahashi T, Wada Y, Yamamoto H (1997) Soft-tissue balancing with pressure distribution during total knee arthroplasty. J Bone Jt Surg Br 79(2):235-239

41. Kutzner I, Bender A, Dymke J, Duda G, von Roth P, Bergmann $G$ (2017) Mediolateral force distribution at the knee joint shifts across activities and is driven by tibiofemoral alignment. Bone $\mathrm{Jt}$ J 99-B(6):779-787

42. Halder A, Kutzner I, Graichen F, Heinlein B, Beier A, Bergmann $G$ (2012) Influence of limb alignment on mediolateral loading in total knee replacement: in vivo measurements in five patients. $\mathrm{J}$ Bone Jt Surg Am 94(11):1023-1029

43. Heller MO, Taylor WR, Perka C, Duda GN (2003) The influence of alignment on the musculo-skeletal loading conditions at the knee. Langenbecks Arch Surg 388(5):291-297

44. Werner FW, Ayers DC, Maletsky LP, Rullkoetter PJ (2005) The effect of valgus/varus malalignment on load distribution in total knee replacements. J Biomech 38(2):349-355

45. Ahmed AM, Burke DL (1983) In-vitro measurement of static pressure distribution in synovial joints-part I: tibial surface of the knee. J Biomech Eng 105(3):216-225

46. Bingham J, Papannagari R, Van de Velde S, Gross C, Gill T, Felson D, Rubash H, Li G (2008) In vivo cartilage contact deformation in the healthy human tibiofemoral joint. Rheumatology 47(11):1622-1627

47. Eckstein F, Lemberger B, Gratzke C, Hudelmaier M, Glaser C, Englmeier K, Reiser M (2005) In vivo cartilage deformation after different types of activity and its dependence on physical training status. Ann Rheum Dis 64(2):291-295

48. Zlotnicki JP, Naendrup J-H, Ferrer GA, Debski RE (2016) Basic biomechanic principles of knee instability. Curr Rev Musculoskelet Med 9(2):114-122

49. Hamada H, Nishii T, Tamura S, Tanaka H, Wakayama T, Sugano $\mathrm{N}$ (2015) Comparison of load responsiveness of cartilage T1rho and T2 in porcine knee joints: an experimental loading MRI study. Osteoarthr Cartil 23(10):1776-1779

50. Herberhold C, Faber S, Stammberger T, Steinlechner M, Putz R, Englmeier KH, Reiser M, Eckstein F (1999) In situ measurement of articular cartilage deformation in intact femoropatellar joints under static loading. J Biomech 32(12):1287-1295

51. Donahue TL, Hull ML, Rashid MM, Jacobs CR (2002) A finite element model of the human knee joint for the study of tibiofemoral contact. J Biomech Eng 124(3):273-280

52. Kleemann RU, Krocker D, Cedraro A, Tuischer J, Duda GN (2005) Altered cartilage mechanics and histology in knee osteoarthritis: relation to clinical assessment (ICRS Grade). Osteoarthr Cartil 13(11):958-963

53. Loeser RF (2011) Aging and osteoarthritis. Curr Opin Rheumatol 23(5):492

54. Englund M, Guermazi A, Lohmander SL (2009) The role of the meniscus in knee osteoarthritis: a cause or consequence? Radiol Clin N Am 47(4):703-712

55. Chaudhari AS, Stevens KJ, Sveinsson B, Wood JP, Beaulieu CF, Oei EH, Rosenberg JK, Kogan F, Alley MT, Gold GE (2019) Combined 5-minute double-echo in steady-state with separated echoes and 2-minute proton-density-weighted 2D FSE sequence for comprehensive whole-joint knee MRI assessment. J Magn Reson Imaging 49(7):e183-e194

Publisher's Note Springer Nature remains neutral with regard to jurisdictional claims in published maps and institutional affiliations. 